\title{
Early genistein exposure of California mice and effects on the gut microbiota-brain axis
}

\author{
Brittney L Marshall1,2, Yang Liu1,3, Michelle J Farrington 1,2, Jiude Mao ${ }^{1,2}$, William G Helferich4, A Katrin Schenk ${ }^{5}$, \\ Nathan J Bivens ${ }^{6}$, Saurav J Sarma1,7, Zhentian Lei1,7,8, Lloyd W Sumner1,7,8, Trupti Joshi1,3,9 and \\ Cheryl S Rosenfeld1,2,3,10,11
}

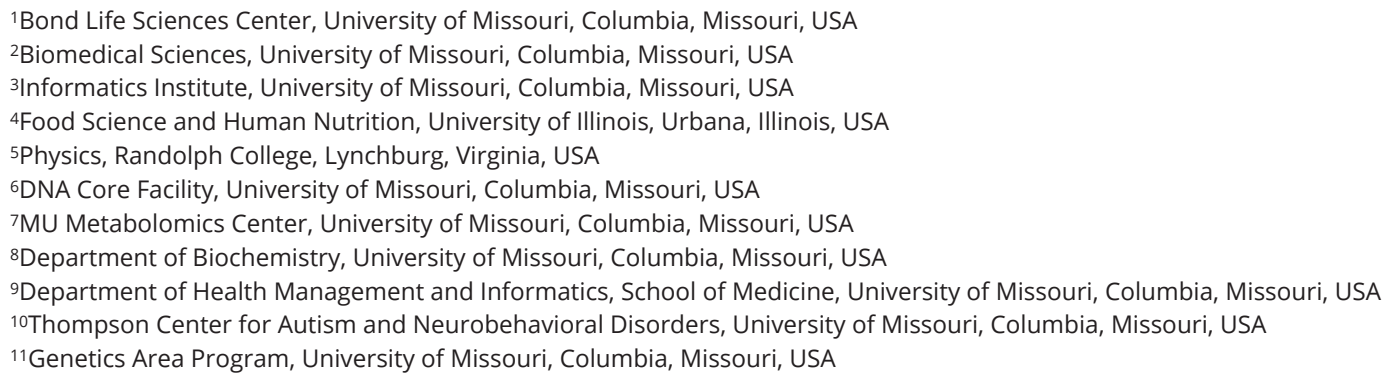

Correspondence should be addressed to C S Rosenfeld: rosenfeldc@missouri.edu

\begin{abstract}
Human offspring encounter high amounts of phytoestrogens, such as genistein (GEN), through maternal diet and soy-based formulas. Such chemicals can exert estrogenic activity and thereby disrupt neurobehavioral programming. Besides inducing direct host effects, GEN might cause gut dysbiosis and alter gut metabolites. To determine whether exposure to GEN affects these parameters, California mice (Peromyscus californicus) dams were placed 2 weeks prior to breeding and throughout gestation and lactation on a diet supplemented with GEN ( $250 \mathrm{mg} / \mathrm{kg}$ feed weight) or AIN93G phytoestrogen-free control diet (AIN). At weaning, offspring socio-communicative behaviors, gut microbiota and metabolite profiles were assayed. Exposure of offspring to GEN-induced sexdependent changes in gut microbiota and metabolites. GEN exposed females were less likely to investigate a novel female mouse when tested in a three-chamber social test. When isolated, GEN males and females exhibited increased latency to elicit their first call, suggestive of reduced motivation to communicate with other individuals. Correlation analyses revealed interactions between GEN-induced microbiome, metabolome and socio-communicative behaviors. Comparison of GEN males with AIN males revealed the fraction of calls above $20 \mathrm{kHz}$ was associated with daidzein, $\alpha$-tocopherol, Flexispira spp. and Odoribacter spp. Results suggest early GEN exposure disrupts normal sociocommunicative behaviors in California mice, which are otherwise evident in these social rodents. Such effects may be due to GEN disruptions on neural programming but might also be attributed to GEN-induced microbiota shifts and resultant changes in gut metabolites. Findings indicate cause for concern that perinatal exposure to GEN may detrimentally affect the offspring microbiome-gut-brain axis.
\end{abstract}

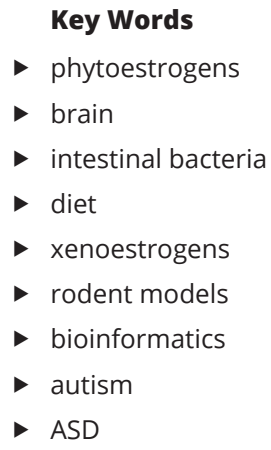




\section{Introduction}

Many infants that are fed soy-based formulas are also exposed to plant phytoestrogens/isoflavones, including genistein (GEN). Additionally, fetuses can be exposed to GEN and other phytoestrogens through the maternal diet. Such chemicals can act similarly to estradiol (E2) and presumably disrupt normal developmental processes, including gonad and brain sexual differentiation. Thus, animal model and human epidemiological studies have been initiated to examine how this chemical affects neonatal development, especially for the reproductive and neurobehavioral systems (Dinsdale \& Ward 2010). Early exposure to isoflavones in soy formula is associated with adverse female reproductive consequences later in life (Jefferson \& Williams 2011, D'Aloisio et al. 2013, Upson et al. 2016). Girls exposed during infancy to soy formula show reduced female-typical play behavior, but comparable disruptions are absent in boys (Adgent et al. 2011). A potential linkage between feeding infant soy formula and subsequent risk for autistic behaviors has been reported (Westmark 2013). Similarly, animal model studies have reported evidence that early exposure to GEN can lead to reproductive (Jefferson et al. 2007, Cimafranca et al. 2010) and behavioral abnormalities such as increased defensive behaviors and demasculinization in male mice (Wisniewski et al. 2005). Developmental exposure of rodents to GEN is associated with increased anxiety and aggressive behaviors, along with altered brain development (Santti et al. 1998, Rodriguez-Gomez et al. 2014).

In pigs, a soy formula diet affects the intestinal epithelial lining, microbial populations and intestinal epithelial barrier as well as anti-inflammatory markers (Yeruva et al. 2016). Rodent and human studies suggest that GEN or soy-based foods can alter the gut microbiome (Piacentini et al. 2010, Fernandez-Raudales et al. 2012, Nakatsu et al. 2014, Bai et al. 2016, Smith-Brown et al. 2016, Wu et al. 2016, Cross et al. 2017, Paul et al. 2017). Soy-fed neonatal White Dutch Landrace pigs show linkages between diet-responsive intestinal metabolites and gut microbes (Piccolo et al. 2017). In a human study, the plasma metabolome of vegans living in a Western society and consuming a soy-rich diet differed from that of omnivores, whereas the gut microbial profile between the two groups of individuals was relatively similar $(\mathrm{Wu}$ et al. 2016). Other studies in mice have shown that direct consumption of GEN and exposure during pre- or postnatal life is associated with gut microbiota changes, and these alterations are linked to metabolic and cognitive changes
(Huang et al. 2018, Lopez et al. 2018, Zhou et al. 2018). Metabolites produced by gut microbes may influence host function (Rosenfeld 2015, Dodd et al. 2017, Schugar et al. 2017, van de Wouw et al. 2017, Zheng et al. 2017, Zhou \& Fang 2018). However, these above studies examining effects of GEN on the gut microbiome did not examine changes in host or microbial metabolites.

It is increasingly being recognized that the gut microbiome through production of metabolites and other potential mechanisms can affect the host's neurobehavioral state, which has been coined the microbiome gut-brain axis (Clarke et al. 2013, Borre et al. 2014, Stilling et al. 2014, Rosenfeld 2015). The first evidence associating gut microbiota disturbances and neurobehavioral disorders originated from germ-free (GF) mice that lack a resident gut microbiome. Such mice demonstrate disruptions in the hypothalamic-pituitary-adrenal gland (HPA) axis that is attenuated with bacterial reconstitution or fecal transplantation (Sudo et al. 2004). GF mice are more anxious, less exploratory and show cognitive and social deficits (Diaz Heijtz et al. 2011, Gareau et al. 2011, Neufeld et al. 2011, Clarke et al. 2013, Desbonnet et al. 2014).

Based on past studies, we hypothesized that developmental exposure to GEN might affect the gut microbiome, metabolome and socio-communicative behaviors either directly or indirectly via the microbiomegut-brain axis. To test this hypothesis, California mice (Peromyscus californicus), who are generally quite social and monogamous, were developmentally exposed to GEN or a phytoestrogen-free control diet and the gut microbiota, metabolome and socio-communicative behaviors were examined at weaning. We chose this species over conventional inbred mouse strains to replicate the genetic diversity present in most human populations.

\section{Materials and methods}

\section{Animals and treatments}

Adult (60-90 days of age) California mouse females and males, free of common rodent pathogens, were purchased from the Peromyscus Genetic Stock Center (PGSC) at the University of South Carolina (Columbia, SC, USA). After shipment to the University of Missouri, they were placed in quarantine, along with sentinel mice, for a minimum of 8 weeks to ensure that they did not carry any transmittable and zoonotic diseases. No diseases have been identified to date in any sentinel or colony animals. Once the animals were deemed disease-free, they were then moved to the 
Animal Sciences Research Center (ASRC). At this facility, we currently have our own breeding colony established. Additional animals have been purchased from the PGSC to maintain the outbred status of the line and similar procedures were followed as listed above. All experiments were approved by the University of Missouri Animal Care and Use Committee (Protocol \#8693) and performed in accordance with the recommendations in the National Institutes of Health Guide for the Care and Use of Laboratory Animals.

To reduce any background bisphenol A (BPA) exposure, weaned animals were housed either in polystyrene (for breeder pairs) or polypropylene cages (for $\mathrm{F}_{1}$ offspring) (Allentown Inc, Allentown, NJ, USA), provided glass water bottles and BPA-free water. Two weeks prior to breeding, virgin females, 8-12 weeks of age were randomly assigned to receive one of two diets: (1) a low phytoestrogen AIN 93G diet supplemented with 7\% by weight corn oil (as a main fatty acid source) rather than soy oil to minimize potential phytoestrogenic contamination (control) or (2) the same AIN93G diet supplemented with $250 \mathrm{mg} / \mathrm{kg}$ GEN, which has previously been shown to affect various parameters in mice (Dolinoy 2006, Dolinoy et al. 2007, Rosenfeld et al. 2013). This amount of GEN results in similar circulating concentrations of genistein as in humans consuming soy-enriched diets (Fritz et al. 2002). Upon weaning (30 days of age) all animals were placed on the AIN diet. This approach was used to replicate the maternal diet exposure of fetuses and neonates to GEN, which can then be transmitted across the placenta and in the milk, respectively. Maternal GEN supplementation was continued until pups were weaned as brain development extends throughout the postnatal period in rodents (Rice \& Barone 2000, Howdeshell 2002).

One male and one female offspring from each litter were selected for subsequent analyses. For all analyses, samples from the same individuals were examined to allow for correlation analyses to be performed. Number of replicates included five AIN females, five GEN females, three AIN males and three GEN males. To determine how many replicates were needed to detect the significant differences, especially for the metabolome and microbiome portions of the study, we consulted previous studies in this area beforehand (Javurek et al. 2016, Paul et al. 2017, Okamoto et al. 2018, Rock et al. 2018). Moreover, we also did our own power analysis with SAS Power and Sample Size application (PSS, SAS Analysis, Cary, NC, USA) that verified this number of replicates should be sufficient to detect differences. Based on our previous microbiome and metabolome studies (Javurek et al. 2016,
Rosenfeld et al. 2018, Vieira-Potter et al. 2018), we also sought to test all samples at the same time to avoid any potential confounding batch effects.

\section{Social behavior testing}

Upon weaning (PND30), the pups underwent a sociability and preference for social novelty three-chambered test, designed to identify social deficits (Moy et al. 2004). We chose this time period to elucidate the potential immediate effects perinatal exposure to GEN might exert on socio-communicative behaviors with deficits in these traits considered one type of autistic-like behaviors in rodent models of autism (Crawley 2007, Silverman et al. 2010). With the interest as to whether xenoestrogens and endocrine disrupting chemicals as a whole are associated with increased risk of autism in children (Braun et al. 2014, Schug et al. 2015), we also sought to test the same life period as to when such disorders are commonly diagnosed in children. The three-chambered test is routinely used to examine for social behavioral deficits in weanling and older mice (Yang et al. 2007, Ryan et al. 2010, Ey et al. 2012, Brielmaier et al. 2014).

One of the goals of the current project was to also to determine if associations existed between GEN-induced gut microbiota changes (experimental detailed below) and behavioral alterations. Past studies have shown that gut microbiota changes induced by other maternal environmental factors are strongly associated with social behavioral deficits (Buffington et al. 2016, Bharwani et al. 2017, Sgritta et al. 2019). Buffington et al. (2016) also established causation of maternal high-fat diet (MHFD)induced gut microbiota changes and social deficits in offspring by supplementing this group of offspring with a single bacterium, Lactobacillus reuteri, that abolished the social deficits and neuropathological changes induced by MHFD. Further, this group confirmed that MHFD-induced gut microbiota changes led offspring social impairments by performing fecal microbial transfer from MHFD mice to GF mice not exposed to this in utero change, which resulted in social deficiencies in the recipient mice that recapitulated those seen in donor individuals exposed to the MHFD. With an interest as to whether developmental exposure to GEN-induced gut microbiota may be linked with neurobehavioral changes, we chose to examine socio-communication behaviors that have already proven vulnerable to shifts in gut microbiota resulting from other in utero manipulations.

The test uses a three-chambered apparatus in which openings between the chambers allow the animal to move 
throughout the apparatus for the duration of the test. The outer two chambers contain wire mesh cups to hold the 'stranger' mice, either Stranger 1 or Stranger 2. The stranger mice originated from different litters than that of the test animal and were of the same sex, approximate age and treatment group as the test individual. For Trial 1 (habituation trial), the left and right chambers were empty. The pup was placed in the center chamber and video-recorded for a 5-min acclimation period using a Logitech Carl Zeiss Tessar HD 1080P (Newark, CA, USA) camera mounted onto a Joby-Gorilla Pod Original Tripod (Daymen US Inc., Petaluma, CA, USA). The pup was then removed, and the two stranger mice were placed under their respective cups for a 5-min acclimation period. For Trial 2, a stranger mouse (Stranger 1) was placed on the right side, and the left side contained an empty cup. The test mouse was then placed in the center chamber and recorded for $10 \mathrm{~min}$. For Trial 3, the previous mouse (Stranger 1) was again placed on the right side, and a novel mouse (Stranger 2) was placed on the left side. The test mouse was again placed in the center chamber and recorded for $10 \mathrm{~min}$.

For these tests, we opted to use conspecific stranger mice, that is, those developmentally exposed to the same maternal treatment, to avoid potential confounding effects that could originate due to stranger individuals from different treatment groups being more or less dominant than the experimental animal. In other words, by mixing experimental and stranger mice, any potential social deficits might also be attributed to aversion of the experimental mouse to interact with strangers of different perinatal exposure background, which is of particular concern in California mice where social dominance can be influenced by extrinsic factors (Rosenfeld \& Trainor 2014). Between each trial, all animals were returned to their cages and the apparatus was cleaned with a 70\% ethanol solution. Data collected from this test were analyzed using Observer software version 11.5 (Noldus, Leesburg, VA, USA), and the animal's location in the threechambered test was coded along with behaviors such as rearing, grooming and nose-to-nose contact with Stranger 1 mouse (trials 2 and 3) and Stranger 2 mouse (trial 3).

\section{Ultrasonic vocalization measurements}

Immediately following the sociability test, the animal was placed in a clean, empty cage and transferred to a polypropylene box containing polypropylene panels lined with 2 inches of convoluted acoustic foam paneling (Soundproof Cow, Chambersburg, PA, USA).
Audio was recorded for $5 \mathrm{~min}$ using an Avisoft Bioacoustics CM16/CMPA40-5V microphone (Glienicke, Germany) plugged into a National Instruments USB 6351 data collection board, which was further connected to a Dell OptiPlex 7010 (Dell Incorporated, Roundrock, TX, USA). Data were collected using a custom code written by the laboratory of Dr Katrin Schenk at Randolph College using MATLAB software (MathWorks, Natick, MA, USA) as detailed previously (Johnson et al. 2017, 2018). These recordings capture audible calls as well as ultrasonic vocalizations (USVs) that are above $20 \mathrm{kHz}$ and out of the hearing range for humans. Vocalizations were segmented (separated from the background noise) and the number of syllables, syllable durations, syllable's median frequencies, average syllable power and power percent below and above $20 \mathrm{kHz}$ were determined using the analysis program (MATLAB software) designed by Dr Katrin Schenk.

\section{Collection of fecal samples and isolation of fecal microbial DNA}

After the behavioral tests were completed, each animal was placed in a cage alone without any bedding. Four to five fecal boli were collected from each animal and placed in a $7 \mathrm{~mL}$ polypropylene vial (Fisher Scientific). As these animals are part of a larger ongoing study to examine for potential longstanding social behavioral deficits, cognitive impairments and anxiogenic behaviors throughout the lifespan, they were not euthanized at the completion of these experiments. Thus, brain, intestine and terminal blood samples were not collected at this time.

The fecal microbial DNA was isolated using the PowerFecal DNA Isolation kit (Mo Bio Laboratories, Inc., Carlsbad, CA, USA) according to the manufacturer's protocol. The quantity of DNA isolated was measured using Qubit 3.0 Fluorometer (Life Technologies). The number of replicates ( $n=3-5$ per group) tested is comparable to that used in other maternal diet and offspring gut microbiome studies that showed that such sample sizes can result in statistical differences between offspring groups (Ma et al. 2014, Thorburn et al. 2015).

\section{$16 S$ rRNA sequencing}

The University of Missouri DNA Core Facility prepared bacterial 16S ribosomal DNA amplicons from extracted fecal DNA by amplification of the V4 hypervariable region of the 16S rDNA with universal primers (U515F/806R) flanked by Illumina standard adapter sequences (Caporaso et al. 2011, Walters et al. 2011). Universal primer sequences 
are available at proBase (http://www.microbial-ecology. net/probebase/) (Loy et al. 2007). A forward primer and reverse primer employing unique, dual indexes were used in each PCR reaction. PCR reactions $(50 \mu \mathrm{L})$ contained $100 \mathrm{ng}$ of genomic DNA, forward and reverse primers (0.2 $\mu \mathrm{M}$ each), dNTPs ( $200 \mu \mathrm{M}$ each) and Phusion HighFidelity DNA Polymerase (1 U). PCR amplification was performed as follows: $98^{\circ} \mathrm{C}(3: 00)+\left(98^{\circ} \mathrm{C}(0: 15)+50^{\circ} \mathrm{C}\right.$ $\left.(0: 30)+72^{\circ} \mathrm{C}(0: 30)\right) \times 25$ cycles $+72^{\circ} \mathrm{C}(7: 00)$. Amplified product $(5 \mu \mathrm{L})$ from each PCR reaction was combined and thoroughly mixed to prepare a single pool. Pooled amplicons were then purified by addition of Axygen AxyPrep MagPCR Clean-up beads $(50 \mu \mathrm{L})$ to an equal volume of $50 \mu \mathrm{L}$ of the amplicon library pool and incubated at room temperature for $15 \mathrm{~min}$. Products were placed on a magnetic stand for $5 \mathrm{~min}$ and supernatant $(95 \mu \mathrm{L})$ removed and discarded. Each well was washed by addition of $200 \mu \mathrm{L}$ of freshly prepared $80 \% \mathrm{EtOH}$, incubated at room temperature for $30 \mathrm{~s}$ and supernatant was removed. Wash steps were repeated once and the plate was allowed to dry on the magnetic stand for 15 min. The dried pellet was resuspended in Qiagen EB Buffer $(32.5 \mu \mathrm{L})$, incubated at room temperature for $2 \mathrm{~min}$, and then placed on the magnetic stand for $5 \mathrm{~min}$. The supernatant $(30 \mu \mathrm{L})$ was transferred to a low binding microcentrifuge tube for storage. The final amplicon pool was evaluated using the Advanced Analytical Fragment Analyzer automated electrophoresis system, quantified with a Qubit flourometer using a quant-iT HS dsDNA reagent kit (Invitrogen), and diluted according to Illumina's standard protocol for sequencing on the MiSeq.

\section{Bioinformatics and amplicon analyses}

Paired-end Illumina MiSeq DNA reads were joined using join_paired_ends.py and combined using add_qiime_ labels.py from QIIME 1.9.1 (Magoc \& Salzberg 2011). Uclust (Edgar 2010) was used to clean contigs and remove those with E $>0.5$ (http://drive5.com/usearch/manual/exp_errs. html). Contigs were clustered to $97 \%$ identity against DNA sequences in the Greengenes database (DeSantis et al. 2006), version 13_8, using the QIIME (Caporaso et al. 2010), version 1.9.1, script pick_open_reference_otus.py, which obviates chimera and PCR error detection with all reads clustered. After OTU picking, we filtered out OTUs with less than two observation counts using the script filter_otus_from_otu_table.py. For alpha-diversity in $F_{1}$ samples, Chao1 (species richness), Shannon (species diversity) values and rarefaction matrices were calculated and plotted using the alpha_rarefaction.py script in the
Qiime package (Caporaso et al. 2010). Measurements of beta-diversity were facilitated by the QIIME script beta diversity.py and jackknifed_beta_diversity.py with PCoA plots generated. Visualization of taxonomy bar-charts were generated using summarize_taxa_through_plots. py from QIIME packages. Permutational multivariate analysis of variance (PERMANOVA) was used to examine for significant difference between groups.

For the subsequent differential abundant OTU and taxonomy analysis, we used the DESeq2 (Love et al. 2014) and negative binomial Wald test using scripts differential_ abundance.py as implemented in QIIME. We selected significant OTUs based on an adjusted $P$ value at the 0.05 level mapping to the Greengenes database. Regulation was determined by assigned $\log _{2}$ fold change calculated from differential analysis. With these methods, relevant pairwise comparisons were performed, such as F-GEN vs F-AIN and M-GEN vs M-AIN.

\section{Gut metabolome analyses}

Metabolomics analyses were performed with the fecal samples from all individuals, as detailed previously (Vieira-Potter et al. 2018) and were used to assess how developmental exposure to GEN affects gut bacterial metabolite profiles. An alkane mix was used for quality control (QC) samples for validation of instrument performance (Sigma). $10 \mu \mathrm{L}$ of $\mathrm{H}_{2} \mathrm{O}$ containing $1 \mu \mathrm{g} / \mu \mathrm{L}$ ribitol (internal standard that was previously validated) and $500 \mu \mathrm{L}$ of $80 \%$ methanol were added to $10 \pm 0.06 \mathrm{mg}$ of each fecal sample. Samples were vortexed for $5 \mathrm{~s}$, sonicated for $15 \mathrm{~min}$ shaken for $2 \mathrm{~h}$ on an orbital shaker at $140 \mathrm{rpm}$, and finally centrifuged at $13,000 \boldsymbol{g}$ for $15 \mathrm{~min}$. $400 \mu \mathrm{L}$ of supernatant was collected into a glass vial, dried under a gaseous nitrogen stream, methoximated in pyridine with $40 \mu \mathrm{L}$ of $15 \mathrm{mg} / \mathrm{mL}$ methoxyamine hydrochloride and then trimethylsilylated with $40 \mu \mathrm{L}$ MSTFA (N-methyl$\mathrm{N}$-(trimethyl-silyl)trifluoroacetamide) $+1 \% \quad$ TMCS (chlorotrimethylsilane) reagent. The derivatized extracts were analyzed, as described previously (Deda et al. 2017). Non-targeted metabolic profiling was performed using an Agilent 6890 GC coupled to a 5973N MSD mass spectrometer with a scan range from $\mathrm{m} / \mathrm{z} 50$ to 650 (Agilent Technologies, Inc.). Separation was achieved with a temperature program of $80^{\circ} \mathrm{C}$ for $2 \mathrm{~min}$, then ramped at $5^{\circ} \mathrm{C} / \mathrm{min}$ to $315^{\circ} \mathrm{C}$ and held at $315^{\circ} \mathrm{C}$ for $12 \mathrm{~min}$, a $60 \mathrm{~m}$ DB-5MS column (J\&W Scientific, $0.25 \mathrm{~mm}$ ID, $0.25 \mu \mathrm{m}$ film thickness) and a constant flow of $1.0 \mathrm{~mL} / \mathrm{min}$ of helium gas. Data were deconvoluted with AMDIS and annotated through mass spectral and retention index matching to 
our in-house constructed spectra library. The unidentified components were then searched and characterized using spectral matching to a commercial NIST17 mass spectral library. The combined identifications were saved as an .ELU file, and the abundance of the ions were extracted using custom MET-IDEA software (Lei et al. 2012). Abundances were then normalized to the ribitol internal standard and used for statistical comparisons.

\section{Statistical analyses}

\section{Behavioral results}

Behaviors in the three-chamber social testing and vocalization parameters were analyzed as detailed previously (Johnson et al. 2017, 2018). Data were analyzed using SAS version 9.4 Software (SAS Institute). Mean differences were determined using Fisher's Protected Least Significant Difference (LSD), as described by Steel (Steel 1997). The LSD was only calculated if the overall $F$ test was significant (Chew \& United 1977, Saville 1990). All data are presented as actual means $(\bar{x})$. The error bars for all figures and reported data represent the standard error of the mean (s.E.M.).

\section{Metabolome}

Multivariate statistical analyses such as 2D PCA, ANOVA, box plots and Volcano plots were performed with the MetaboAnalyst 3.0 program after data pre-treatments, i.e., normalization to the sum, log transformation and Pareto scaling (http://www.metaboanalyst.ca/). Changes in metabolite abundances were considered statistically significant when their $P$ values were $\leq 0.05$. This program was also used to determine the overall metabolite changes in the GEN vs CON (AIN) groups and pathways predicted to be affected in the GEN male and female offspring. A Venn diagram was generated using http://www. interactivenn.net/ (Heberle et al. 2015).

\section{Integrative correlation analyses}

We used the mixOmics R package (Rohart et al. 2017) to correlate the bacterial genera changes simultaneously with fecal metabolome and behavioral results, which enabled the integration of the microbiome, metabolome and mouse behavioral, social and vocalization data. We conducted sparse discriminant analysis with partial least square regression with function 'block.splsda'. The circos plot was generated using the 'circosPlot' function with correlations calculated using the method from González et al. (2012) and 0.9 correlation was used as the cutoff.
It shows together the correlation between each individual features pairs from all four datasets.

\section{Results}

\section{Socio-communicative behaviors}

As detailed above, F1 male and female California mice were tested in three trials in the three-chamber social test with $\mathrm{T} 1$ trial being considered the habituation period. In $\mathrm{T} 2$ trial, one stranger mouse placed on one side of the chamber and an empty cup on the other, no treatment differences in location within the apparatus (left, middle or right) or nose-to-nose contact with Stranger 1 mouse were detected. However, in T3 trial, when a second stranger mouse was introduced, differences in noseto-nose contact for females emerged with AIN females predictably spending more time investigating the novel Stranger 2 mouse than Stranger 1 mouse $(P=0.001$, Fig. 1$)$. In contrast, GEN-exposed females (F-GEN) spent equal time in this trial with Stranger 1 and Stranger 2 mice, suggesting reduced social behavior or interest in seeking out novel individuals.

For vocalization responses, a significant main effect based on maternal treatment was detected for latency to exhibit first call $(P \leq 0.05)$, but no significant interactive effects for maternal treatment $x$ sex were observed. Thus, for this category, male and female data within each treatment group were combined together. When vocalization responses were measured after the three-chambered social test, F1 GEN-exposed individuals took twice as long to elicit their first syllable (call) as AIN control mice ( $P=0.03$, Fig. 2 ),

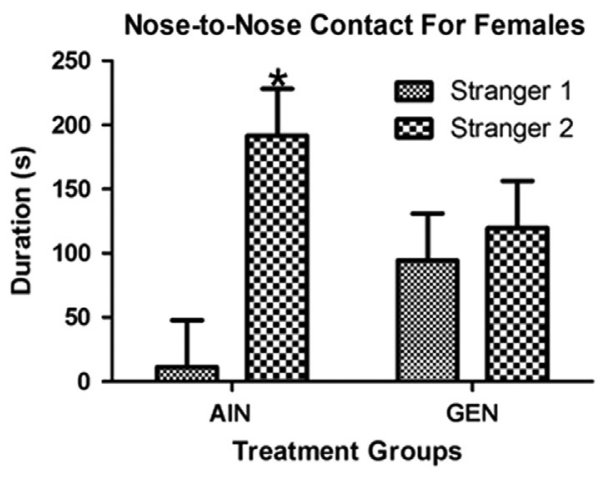

\section{Figure 1}

Number of times F1 females engaged in nose-to-nose contact in T3 trial with Stranger 1 and 2 mice. AIN females spent more time investigating a novel, Stranger 2, mouse than previously acquainted mouse, Stranger 1. However, such differences were not observed in GEN-exposed females who spent equal time in this trial in contact with Stranger 1 and Stranger 2 mice, suggestive of reduced social behaviors. * $P=0.001$ based on time spent with Stranger 2 mouse for AIN females vs GEN females. 
supporting the idea that developmental exposure to GEN reduces socio-communicative behaviors. None of the other vocalization parameters differed between the two groups or based on offspring sex.

\section{Gut microbiota}

Based on $t$-test analyses, no overall differences in $\alpha$-diversity (chao-1 and Shannon analyses) were observed based on developmental exposure of males or females to GEN (Fig. 3). Bar plots of operational taxonomic units (OTU) in F-AIN, F-GEN, M-AIN and M-GEN revealed some potential but not overt bacterial differences (Fig. 3, as several bacteria are represented by Fig. 3C, a legend for the various bacteria are provided in Supplementary Figs 1, 2, 3 and 4 (see section on supplementary data given at the end of this article to allow for each to be legible). Weighted PERMANOVA analyses of the PCA plot revealed significant differences based on GEN exposure and offspring sex $(P=0.003)$ (Fig. 3D). All four groups are shown in this figure to compare the $\alpha$ - and $\beta$-diversity across all groups.

Further pairwise examination with DESeq2 (Love et al. 2014) and negative binomial Wald test, revealed that select bacteria were altered based on GEN exposure and offspring sex. Relative amounts of Lactobacillus spp., Ruminococcus flavefaciens, Bacteroidales and Clostridiales were reduced in GEN-exposed females, whereas Rikenaceae, Ruminococcaceae, Lachnospiraceae and Lactococcus spp. were elevated in this group (Supplementary file 1). In males, GEN decreased the relative abundance of Flexispira spp., Clostridiales, Bacteroidales, Odoribacter spp. and Desulfovibrionaceae but increased the relative abundance of Lachnospiraceae and Allobaculum spp. (Supplementary file 2).

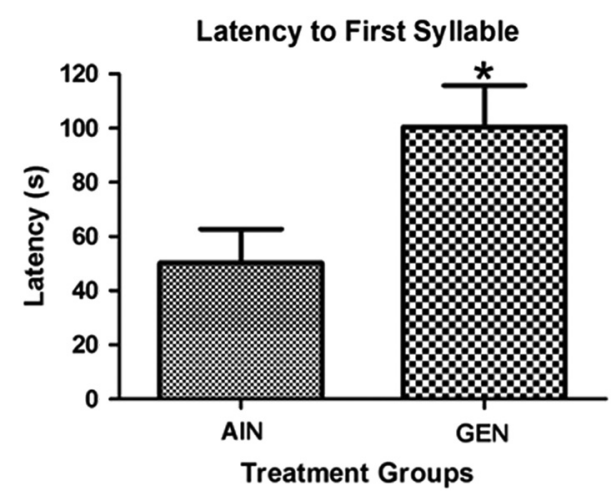

Figure 2

Latency to first syllable (call). GEN-exposed males and females took twice as long to elicit their first syllable (call) as AIN individuals. ${ }^{*} P=0.03$.

(C) 2019 Society for Endocrinology Published by Bioscientifica Ltd.
Printed in Great Britain

\section{Gut metabolome}

GS-MS data were processed using AMDIS software. Metabolite identifications reported are either level 1 or 2 according to the Metabolomics Standards Initiative and specifically those related to metabolite identification (Sumner et al. 2007). A total of 528 components were detected and 278 were annotated by searching our in-house and NIST17 MS spectral libraries (Supplementary files 3 and 4). Two-dimensional (2D) principal component analyses (PCA) revealed male mice developmentally exposed to genistein were separated from the rest of the groups and some separation based on offspring sex (F vs $\mathrm{M}$ ) and maternal treatment (GEN vs $\mathrm{CON}$ ) was evident (Fig. 4). Differential clustering was confirmed by analyzing for significant differences with a Volcano plot for GEN-exposed females vs AIN control females and GEN-exposed males vs AIN control males (Fig. 5). The Volcano plot is a combination of fold change and $t$-test $P$ values. Components with a fold change greater than 2 and a $t$-test $P$ value less than 0.05 are considered significantly different. We report here $P$ values rather than adjusted $P$ values because while adjusted $P$ value reduces the number of false positives, it also reduces the number of true discoveries. Since this is an exploratory experiment, we believe it is appropriate and necessary to use $P$ values in order to avoid missing some significant metabolite differences.

In females, the relative accumulation of several metabolites was altered by developmental exposure to GEN (Supplementary file 5). Malonic acid and methyl heptadecanoate were increased in F-GEN individuals, whereas 4-aminobutyric acid, cysteine, homoserine and ornithine were decreased in this group (Fig. 6). 3-Amino isobutanoic acid was elevated in GEN-exposed males (M-GEN), but methyl linoleate, N2-acetyl-ornithine, daidzein, $\alpha$-tocopherol and 2 $2 \beta, 4 \beta$-choestan-3-ol were reduced in this group (Fig. 7). The full list of metabolites altered in M-GEN is detailed in Supplementary file 5.

The overview of the significantly changed metabolites can be visualized in Supplementary Fig. 5 showing a number of overlap and unique metabolites that were significantly regulated in each comparison. The data show that very few common metabolites were found to be significantly change based on treatment $\times$ sex interactions.

Two pathways significantly affected in F-GEN individuals relative to F-AIN group include methionine and glutamate metabolism and carnitine synthesis (Fig. 8, FDR $\leq 0.05)$. Supplementary Figure 6 shows these two pathways and denotes those metabolites within them 

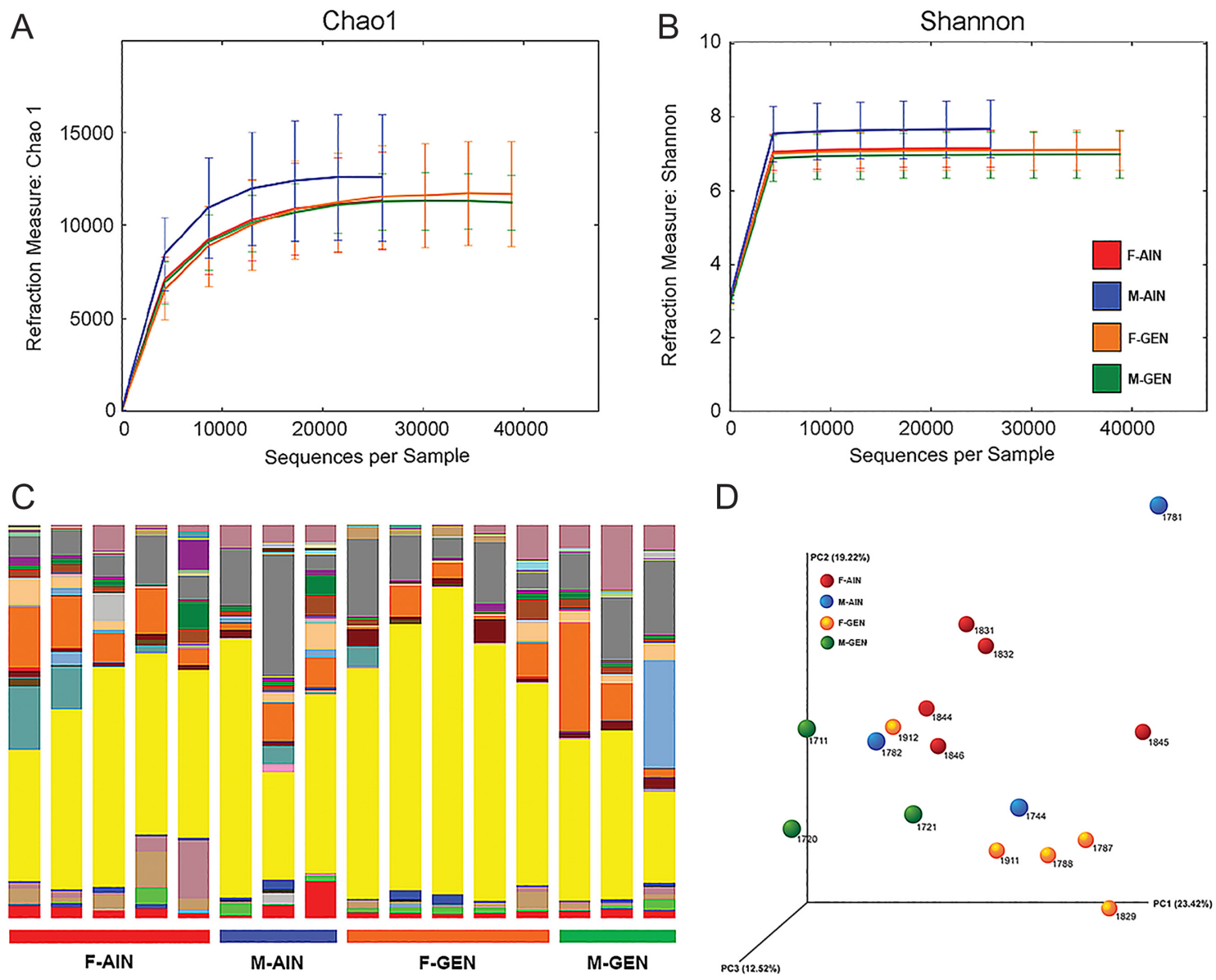

\section{Figure 3}

Measures of $\alpha$ - and $\beta$-diversity in AIN and GEN-exposed F1 males and females. (A and B) Developmental exposure of males and females to GEN did not affect overall differences in species richness (as shown by Chao1 results) and diversity (as shown by Shannon results). The data were plotted using phyloSeq R package plot_richness function (McMurdie and Holmes 2013). (C) Bar plot analysis of the most abundant bacterial species in all three treatment groups for F1 males and females. (D) 3D PCoA analysis F1 male and female offspring results. Weighted PERMANOVA $(P=0.003)$. All four treatment groups are included in these figures to allow for comparison of $\alpha$ - and $\beta$-diversity across all groups. A full colour version of this figure is available at https://doi.org/10.1530/JOE-19-0214.

that were affected by GEN exposure. After FDR correction, no overall pathways were significantly altered in M-GEN vs M-AIN.

\section{Integrative correlation analyses between gut microbiota, gut metabolome and socio-communicative behaviors}

To correlate the gut microbiota changes with gut metabolome and behavioral results, we used the mixOmics R package (Rohart et al. 2017). Four multianalyses comparisons were tested: F-GEN vs F-AIN, M-GEN vs M-AIN, F-GEN vs M-GEN and F-AIN vs M-AIN. Comparison of F-GEN to F-AIN revealed that the only correlations that were significant at 0.9 were average vocalization power positively correlated with Rikenaceae and Ruminococcaceae, both of these bacteria were elevated in F-GEN (Fig. 9). Comparison of M-GEN with M-AIN revealed several significant correlations among the gut metabolome, gut microbiome and behaviors (social and vocalization) at 0.9 (Fig. 10). Some example correlations in GEN-exposed males vs control males include ornithine,

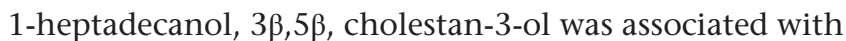
Odoribacter spp. and Bacteroidales. 1-heptadecanol was also associated with Flexispira spp., Odoribacter spp., and Flexispira spp. were associated with $3 \beta, 5 \alpha$, cholestan-3-ol and daidzein. All these bacteria and metabolites were positively associated with fraction of calls above $20 \mathrm{kHz}$, along with $\alpha$-tocopherol.

When comparing within GEN and AIN groups, sex differences were evident. Comparison of M-GEN to F-GEN revealed such correlations as valine was associated with 


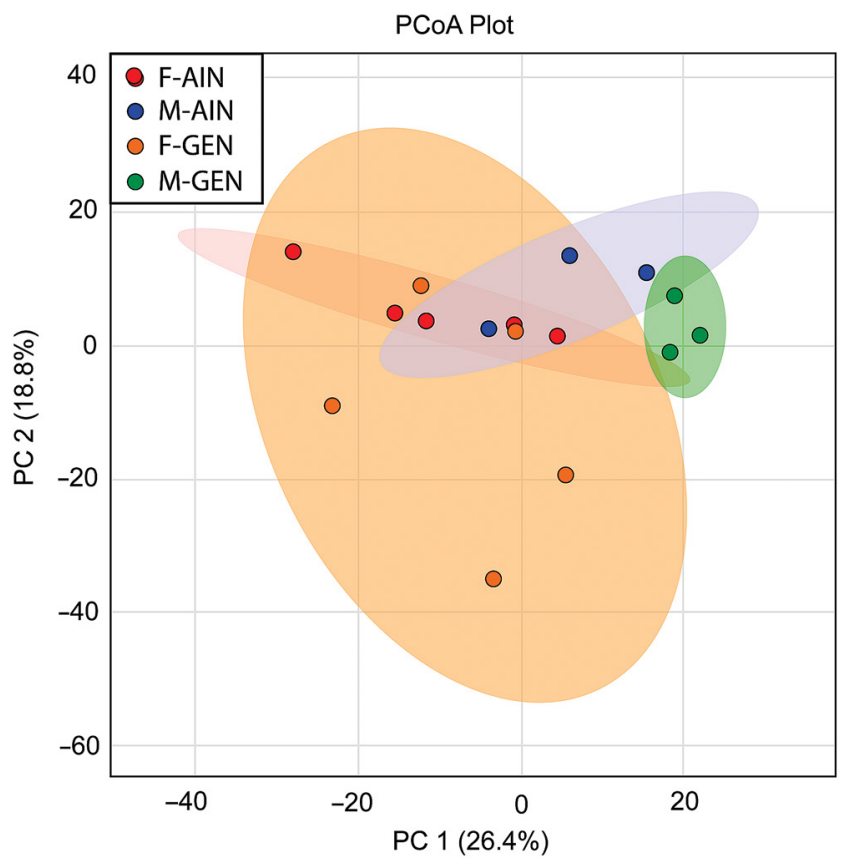

Figure 4

2D PCA analysis of F1 gut metabolome results. The 2D PCA analysis shows some clustering based on developmental exposure to GEN and offspring sex. A full colour version of this figure is available at https://doi. org/10.1530/JOE-19-0214.

Clostridiales and Ruminococcus gnavus (Fig. 11). Cadaverine was associated with Odoribacter spp., Oscillospira spp. and Ruminococcus gnavus. Cholic acid was associated with Rikenellaceae. Total number of calls was associated with cadaverine, Odoribacter spp., Oscillospira spp. and Rumnicoccus gnavus. Latency to produce the first call was associated with cholic acid and Rikenellaceae. Comparison of M-AIN vs F-AIN revealed fewer significant correlations (Fig. 12). One example was average power above and below $20 \mathrm{kHz}$ was positively associated with alanine. The individual pairwise comparisons for these four analyses are included in Supplementary Figs 7, 8, 9 and 10. Supplementary file 6 provides all of the comparisons, and those with correlations $\geq 0.9$ are highlighted.

\section{Discussion}

The first goal of the current study was to determine whether developmental exposure to GEN induces direct effects on subsequent socio-communicative responses. Secondly, we sought to determine whether early contact with this xenoestrogen might affect gut microbiota, fecal metabolites, and thereby result in indirect CNS effects via the microbiome-gut-brain axis. The current findings support previous human and rodent studies suggesting that phytoestrogens in soy formula and GEN can result in subsequent neurobehavioral disruptions, as we have seen with ethinyl estradiol (estrogen present in birth control pills) and BPA (Jasarevic et al. 2011, 2013, Williams et al. 2013, Johnson et al. 2015). Reduced social behaviors, as evidenced by willingness to interact with a novel mouse, were observed in female California mice developmentally exposed to GEN. GEN-exposed males and females took longer to vocalize when placed in isolation. Current rodent data are similar to human epidemiological reports suggesting that soy infant formula consumption is associated with reduced female-typical play behavior in girls and increases the risk of autistic behaviors (Adgent et al. 2011, Westmark 2013). In male rodents, developmental exposure to GEN increases anxiogenic and aggressive behaviors, in spite of
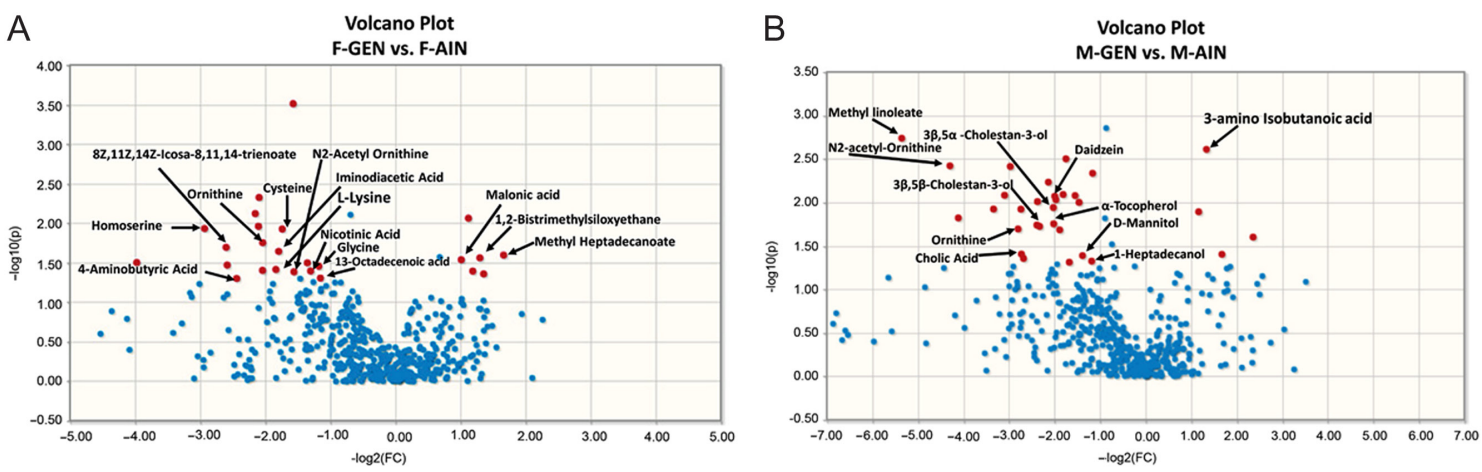

\section{Figure 5}

Volcano plots of metabolites that differ between GEN and AIN females and males. (A) This analysis revealed several metabolites that differed between GEN-exposed females and AIN females. (B) This analysis revealed several metabolites that differed between GEN-exposed males and AIN males. In each figure, the blue dots represent metabolites that were not significantly different between the two groups, whereas, the red dots represent those that are significantly different between the two groups $(P \leq 0.05)$. Characterized metabolites are accordingly labeled. A full colour version of this figure is available at https://doi.org/10.1530/JOE-19-0214. 
Box Plots F-GEN vs. F-AIN (UP in GEN)
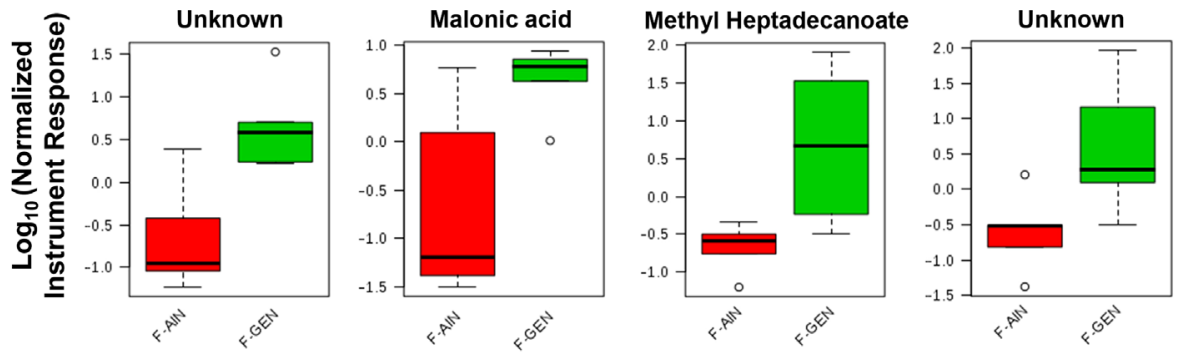

Box Plots F-GEN vs. F-AIN (DOWN in GEN)
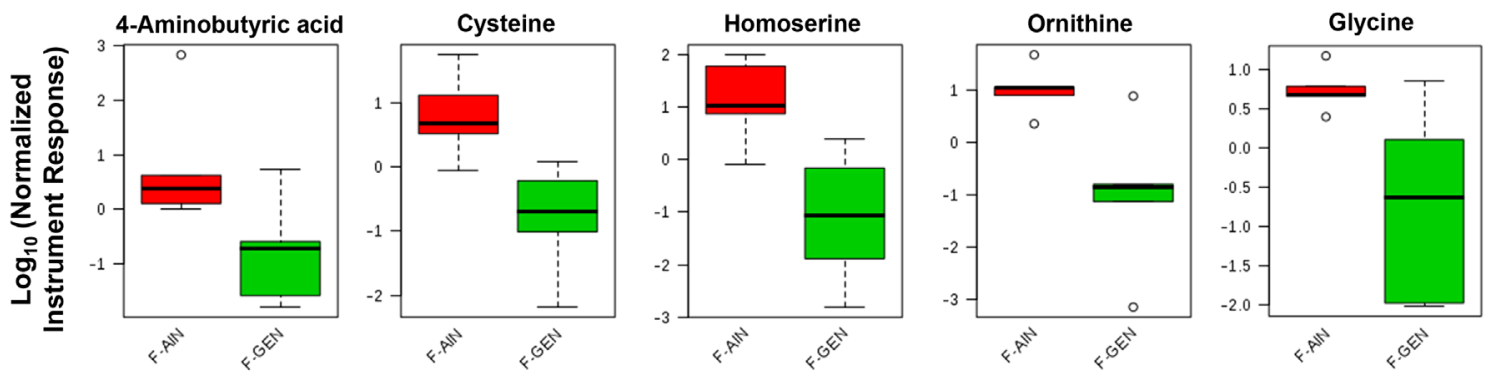

Figure 6

Traditional box plots for metabolites elevated in F-GEN vs. F-AIN groups $(P<0.05)$. The $y$-axes are log 10 values of the normalized instrument response for the labeled metabolites in F-GEN and F-AIN groups (x-axes). The program arbitrarily assigns color codes for the various groups. The box plot upper and lower brackets represents $\pm(1.58$ * interquartile range-IQR/squared root of sample size). A complete list of metabolites that differed between these two groups, as well as directionality, is included in Supplementary file 5. A full colour version of this figure is available at https://doi.org/10.1530/JOE-19-0214.
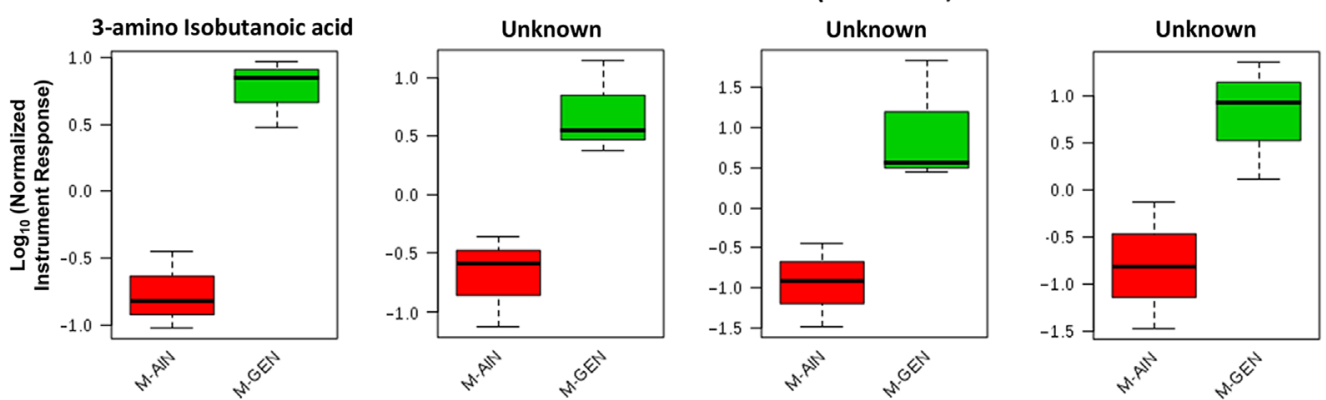

Box Plots M-GEN vs. M-AIN (DOWN in GEN)
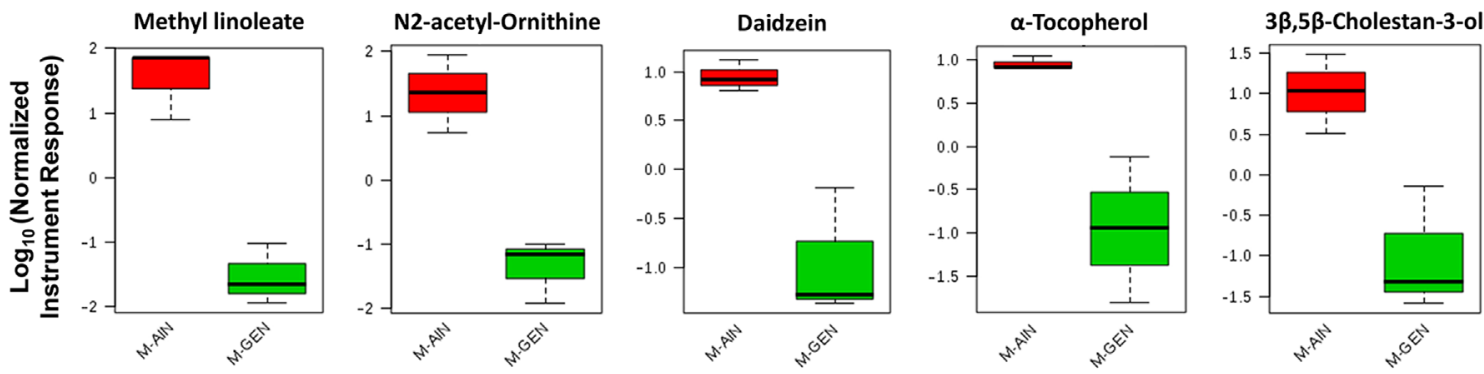

Figure 7

Traditional box plots for metabolites elevated in M-GEN vs. M-AIN groups $(P<0.05)$. The $y$-axes are log 10 values of the normalized instrument response for the labeled metabolites M-GEN vs M-AIN groups (x-axes). The program arbitrarily assigns color codes for the various groups. The box plot upper and lower brackets represents \pm (1.58 * interquartile range-IQR/squared root of sample size). A complete list of metabolites that differed between these two groups, as well as directionality, is included in Supplementary file 5. A full colour version of this figure is available at https://doi.org/10.1530/JOE-19-0214. 


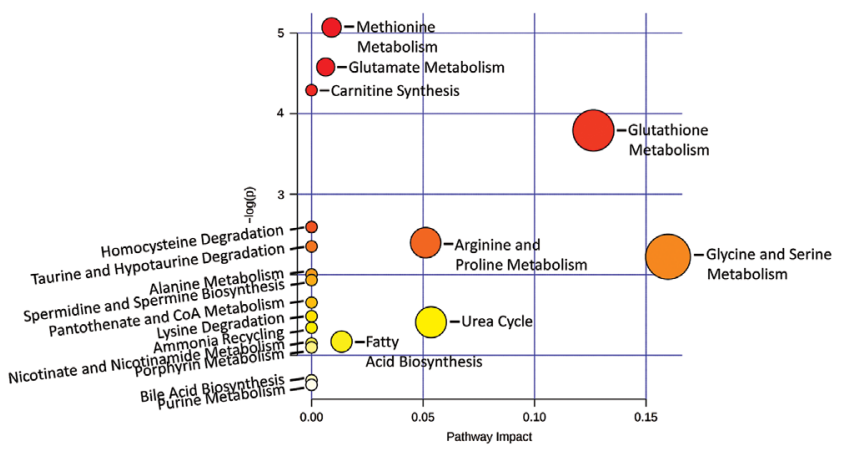

Figure 8

Metabolome view of pathways predicted to differ in F-GEN vs. F-AIN groups as determined using Metaboanalyst webserver. For comparison among different pathways, the program calculates the node importance values from a centrality measure, which are further normalized by the sum of the importance pathways. The total or maximum importance of each pathway is 1 . The $x$-axis shows the impact of the set of significantly different metabolites on a pathway and $y$-axis shows the $-\log (p)$ values of this correlation between the set of significantly different metabolites and the pathways. A full colour version of this figure is available at https://doi. org/10.1530/JOE-19-0214.

the fact that some reports suggest that this xenoestrogen might disrupt brain masculinization (Santti et al. 1998, Wisniewski et al. 2005, Rodriguez-Gomez et al. 2014).
Male rats provided a soy-supplemented diet enriched with GEN and daidzein showed similar anxiogenic responses and engaged in less social interactions (Hartley et al. 2003). Japanese quail (Coturnix japonica) exposed in ovo to GEN showed compromised mating behaviors in adulthood (Viglietti-Panzica et al. 2007). Our current studies are unique in that we sought to determine whether GEN affects the microbiome-gutbrain axis.

Such behavioral changes might be due to direct effects on the brain, especially the hypothalamus. Early exposure to GEN has been reported to cause vacuolization of oxytocin neurons in the neonatal mouse hypothalamus (Yoshimura et al. 2011). GEN may alter brain nitrergic and vasopressinergic circuitry systems in rodents and Japanese quail (Scallet et al. 2003, Viglietti-Panzica et al. 2007, Ponti et al. 2017). The gonadotropin releasing hormone network and hypothalamic-pituitary-adrenal axis might also be affected by GEN exposure (Levy et al. 1995, WojcikGladysz et al. 2005, Medigovic et al. 2012, Trifunovic et al. 2012, Arispe et al. 2013, Mueller \& Heger 2014). While socio-communicative deficits observed in GEN-exposed California mice might be attributed to changes in these

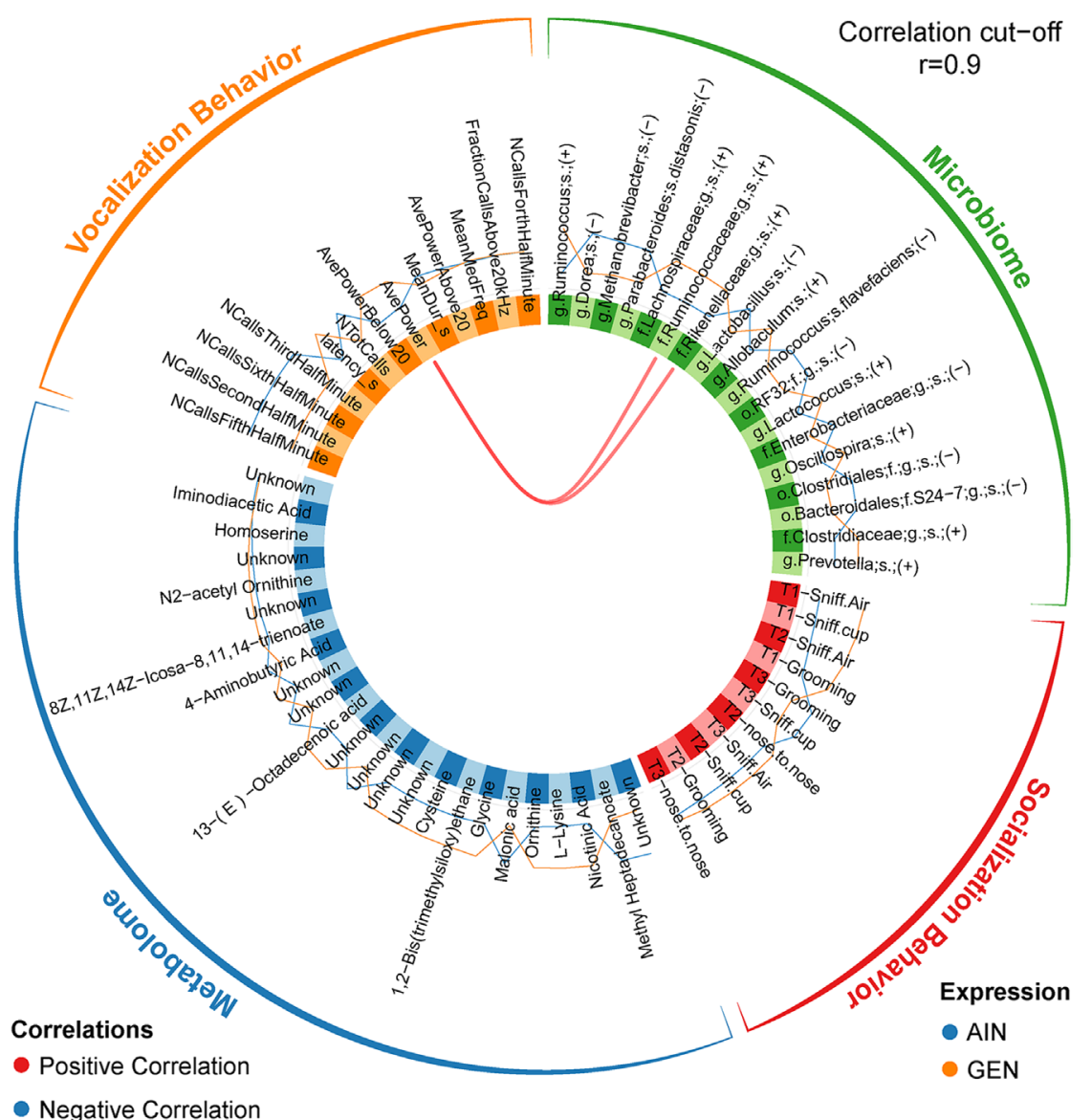

Figure 9

Circos correlations among taxa altered in fecal microbial community of F-GEN vs F-AIN individuals and fecal metabolomic changes due to GEN exposure. A full colour version of this figure is available at https://doi.org/10.1530/JOE-190214. 


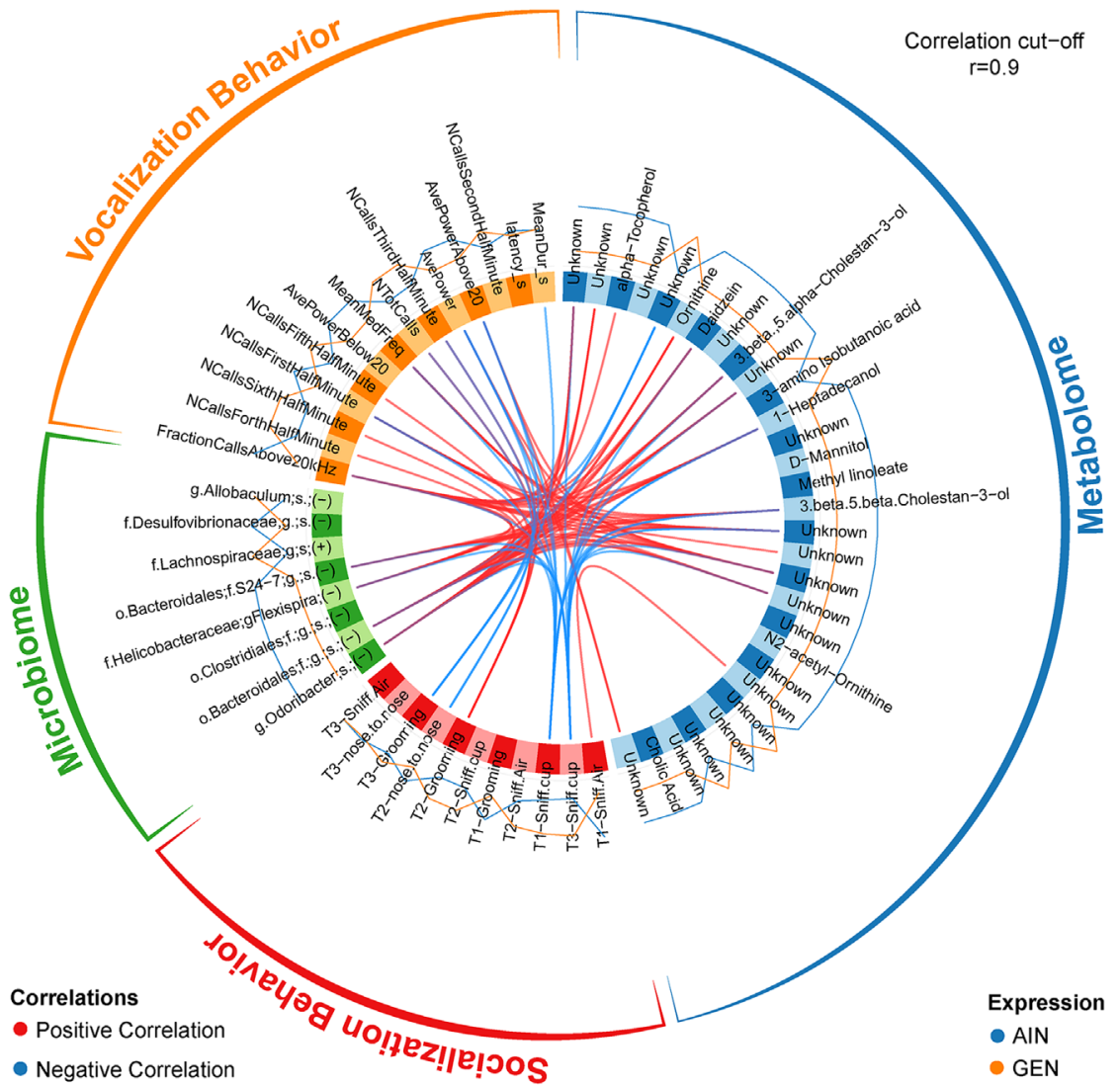

\section{Figure 10}

Circos correlations among taxa altered in fecal microbial community of M-GEN vs M-AIN individuals and fecal metabolomic changes due to GEN exposure. A full colour version of this figure is available at https://doi.org/10.1530/JOE-190214. hypothalamic pathways, such effects could be due to gut dysbiosis and shifts in gut metabolites.

Developmental exposure to GEN led to sex-dependent gut microbiota changes even though xenoestrogen did not affect the overall species richness and diversity. Our expectation was that GEN exposure would lead to similar gut microbiota changes as we previously identified in ethinyl estradiol (EE)-exposed female California mice (Javurek et al. 2016). However, the bacterial changes identified in GEN-exposed individuals did not resemble the profile identified in EE-exposed individuals. Instead, select bacteria showed the opposite pattern with the relative amounts of Rikenellaceae and Prevotella spp. increased in GEN-exposed females but reduced in EE-exposed females. Similarly, we previously found that exposure to bisphenol A led to a unique signature pattern of bacteria in male and female California mice (Javurek et al. 2016). A previous study in mice developmentally exposed to GEN showed that members of the Rikenellaceae family were increased by this phytoestrogen (Zhou et al. 2018), although this study did not separate offspring based on sex. Another study reported that perinatal exposure to GEN increased Enterobacteriales in PND 90 female offspring (Huang et al. 2018). This bacterial order was not affected in the current studies with PND 30 offspring.

Previous studies in animals and humans consuming soy products or exposed to GEN indicate that the gut bacterial changes might depend upon type of phytoestrogen exposure, host species examined and time and duration of exposure to phytoestrogens (Piacentini et al. 2010, Fernandez-Raudales et al. 2012, Nakatsu et al. 2014, Bai et al. 2016, Smith-Brown et al. 2016, Wu et al. 2016, Yeruva et al. 2016, Cross et al. 2017, Paul et al. 2017, Piccolo et al. 2017). GEN-induced changes in gut microbes might alter host responses, as shown previously (Cross et al. 2017). Rats provisioned with a phytoestrogenrich diet demonstrated changes in fecal microbiota that were positively associated with improved cardiometabolic outcomes (Cross et al. 2017). In the current studies, GENinduced gut microbe changes showed sex-dependent associations with socio-communicative behaviors. However, such correlations only indicate that these changes track together; they do not indicate causation. To establish causation that bacterial changes due to GEN exposure result in socio-communicative alterations, fecal microbial transfer from GEN-exposed individuals into GF mice that lack resident gut microbiota and who have not 


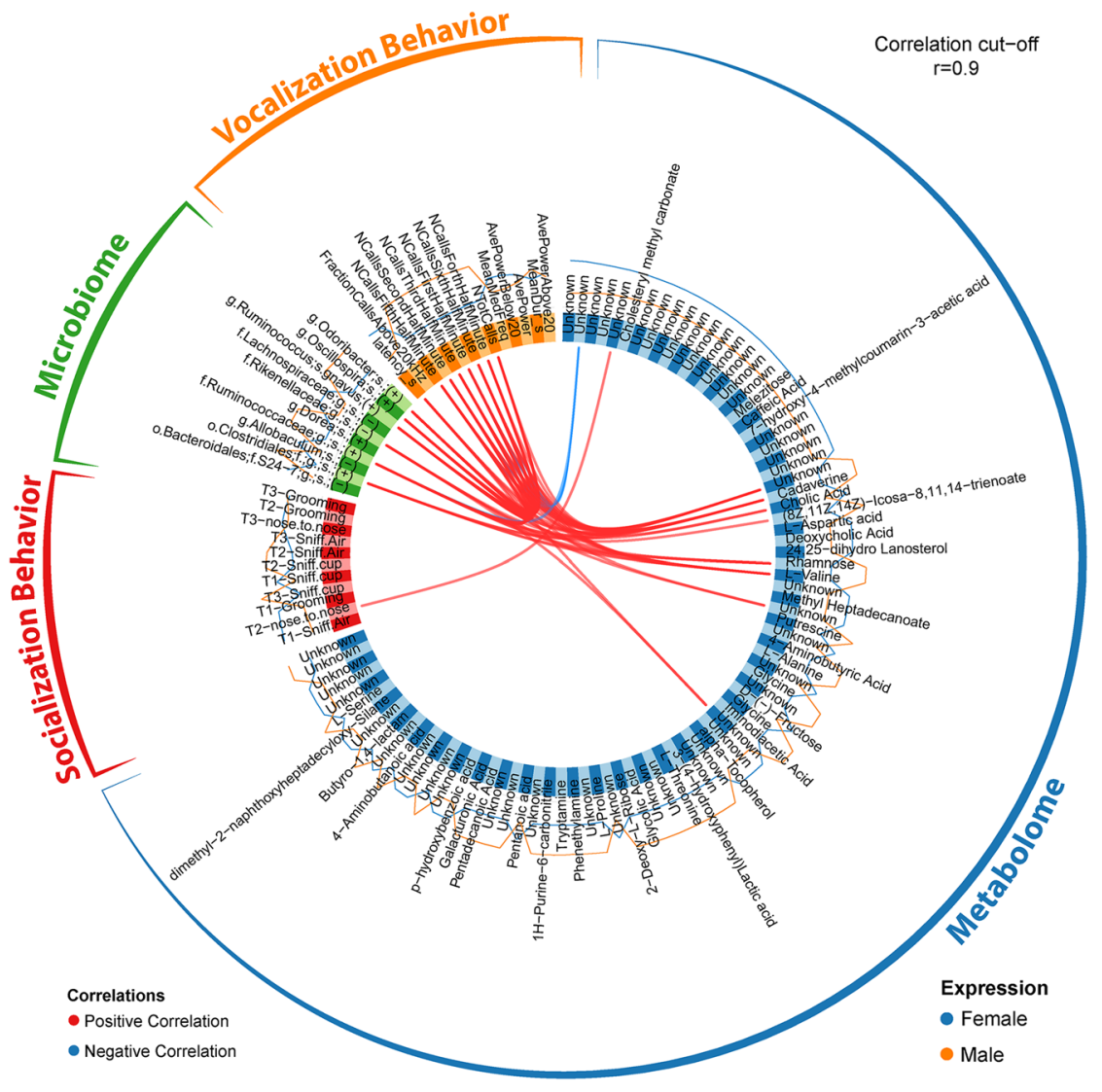

\section{Figure 11}

Circos correlations among taxa altered in fecal microbial community of M-GEN vs F-GEN individuals and fecal metabolomic changes. A full colour version of this figure is available at https:// doi.org/10.1530/JOE-19-0214. been exposed to GEN would be needed, as was done for fecal samples from offspring exposed to MHFD to GF mice with GF recipients then developing similar social deficits as the donor mice (Buffington et al. 2016). Unfortunately, our current animal facility does not have the ability to maintain GF mice. Thus, we are currently exploring such studies through potential collaborations with those at other institutes who have a GF mouse facility.

By altering the gut microbiota, GEN likely affects gut metabolome profiles. Soy-fed neonatal White Dutch Landrace pigs show linkages between diet-responsive intestinal metabolites and gut microbes (Piccolo et al. 2017). However, the plasma metabolome of vegans living in a Western society and consuming a soy-rich diet differed from that of omnivores, whereas the gut microbial profile between the two groups of individuals was surprisingly similar (Wu et al. 2016). In female California mice, GEN exposure predominantly decreased several metabolites, including 4 (gamma)-aminobutyric acid (GABA), cysteine, homoserine, ornithine and glycine. Deficiencies in GABAergic synaptic pathways are linked with mouse models of autism and other human neurobehavioral disorders (Han et al. 2012, Politte et al. 2014, Tso et al. 2015, Chau et al. 2017). Methionine and glutamate metabolism pathways might be disrupted in GEN-exposed females. Disturbances in glutamate metabolism are associated with autism and autistic-like behaviors in animal models of this disorder (Bristot Silvestrin et al. 2013, Fung \& Hardan 2015, Wei et al. 2015). Several discrete metabolites were upregulated (such as 3-amino-isobutanoic acid) and downregulated (e.g. methyl linoleate, N2-acetylornithine, daidzein, $\alpha$-tocopherol and $3 \beta, 5 \beta$-choesetan3-ol) in males.

Importantly, the current studies are the first to show clear sex-dependent linkages between gut metabolites altered in response to developmental exposure to GEN and subsequent socio-communicative disorders. In our recent work, we similarly determined that SOY-induced gut metabolite shifts correlated with host cardiometabolic outcomes (Vieira-Potter et al. 2018). As with the correlations between gut microbes and neurobehavioral responses, the conclusion that changes in select metabolites cause subsequent neurobehavioral alterations cannot be definitively drawn. To establish causation, metabolites identified to be enriched with GEN exposure would need to be administered to control dams and offspring neurobehavioral responses examined throughout the lifespan. Such a post-metabolite approach was done with 


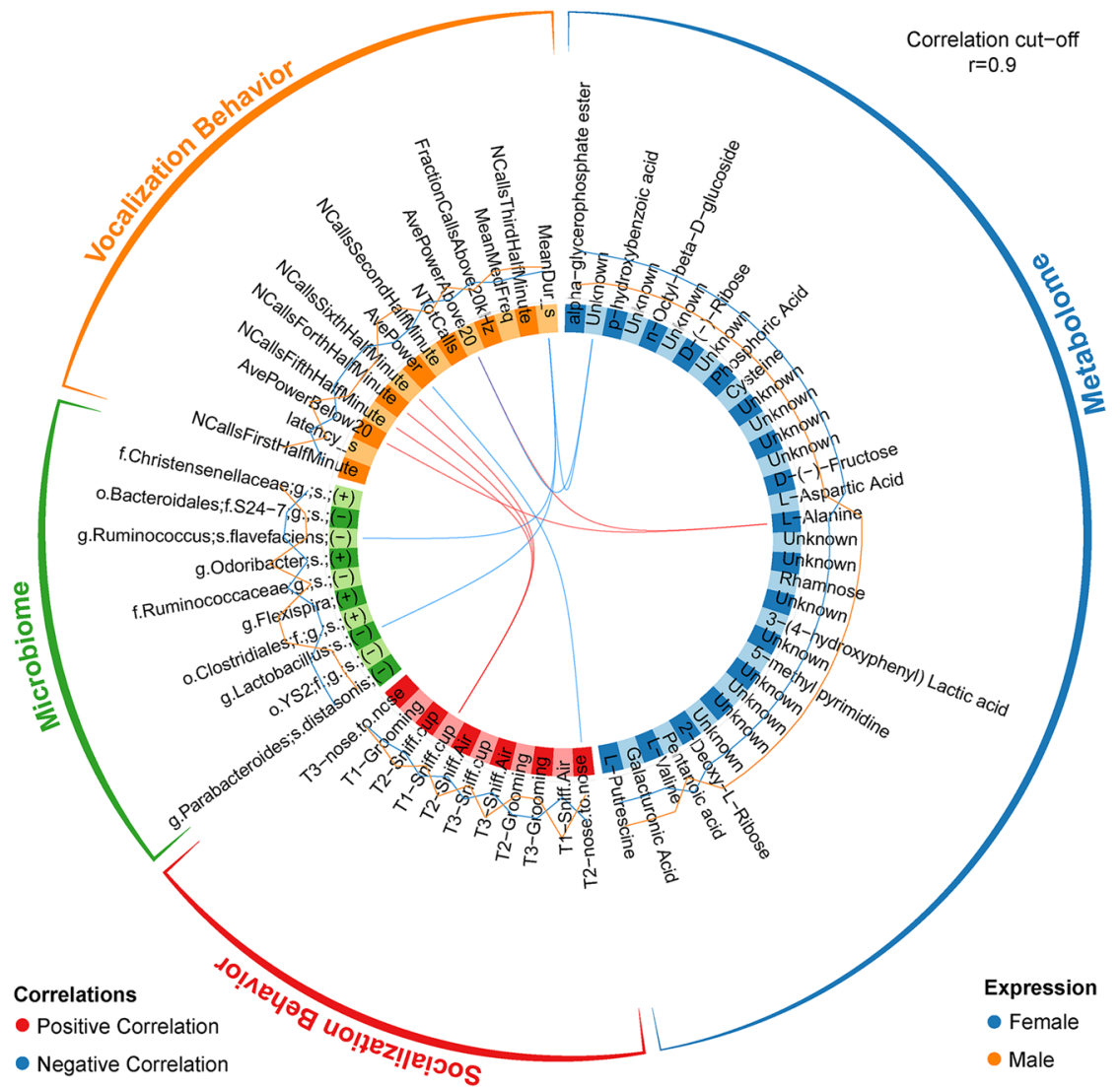

\section{Figure 12}

Circos correlations among taxa altered in fecal microbial community of M-AIN vs F-AIN individuals and fecal metabolomic changes. A full colour version of this figure is available at https:// doi.org/10.1530/JOE-19-0214. 4-ethylphenylsulfate (4-EPS), which triggered autistic-like behaviors in control mice (Hsiao et al. 2013).

Using a multi-Omics approach, we were able to integrate the gut microbiota, metabolome and behavior results and show sex-dependent inter-relationships between these three categories. For instance, GEN males had reductions in Bacteroidales, and this bacterium was positively associated with 1-heptadecanol and $3 \beta, 5 \beta$, cholestan-3-ol. All of these factors, along with other bacteria and metabolites, were positively associated with aspects of socio-communication behaviors.

Potential limitations of this study include the fact only correlation analysis can be between gut microbiota/ metabolite changes and behavioral responses. With the systemic approach used, we cannot tease apart the direct effects GEN might have on the brain vs those that are due to alterations in gut microbiota/metabolites. This approach was chosen to replicate how offspring are likely exposed to GEN during the pre- and postnatal periods. To disentangle neurobehavioral effects directly due to GEN exposure vs those mediated by the gut microbiomemetabolome, intracerebroventricular (ICV) injection with radioactive labeled GEN might be performed in neonatal animals, as has been done for other estrogenic compounds (Dominguez-Ordonez et al. 2015, 2016, Frankiensztajn et al. 2018). This method is likely, however, to be quite challenging to do for individual fetuses. Radioactivelabeled GEN might also be administered via the maternal diet to better trace the systemic distribution of this compound in the offspring.

As the animals were not collected at the end of these current studies, sufficient blood for plasma metabolome studies could not be collected. However, bacterial metabolites might be transmitted to the brain both through the circulatory system and vagal nerve conduction (Bercik et al. 2011, Petra et al. 2015, Rosenfeld 2015, Liu 2017, Bonaz et al. 2018, Jaglin et al. 2018). Gut microbiota changes are often associated with intestinal system pathologies, including increased gut permeability and influx of inflammatory cells that could also impact the brain (Rosenfeld 2015). Because animals were not killed at the completion of these current studies, no assessments could also be made on how developmental exposure to GEN affects the host gastrointestinal system. Future work will explore for such GEN-induced alterations. 


\section{Conclusions}

Our study is the first to show that developmental exposure to GEN leads to socio-communicative deficits in California mice, especially in females. While such effects might be due to direct disruptions on the neural circuitry, especially in the hypothalamus, the observed changes might also be due to GEN stimulated alterations in the microbiome-gut-brain axis. Multi-integrative correlation analyses revealed several interactions between GENinduced microbiome, metabolome and resulting changes in socio-communicative behaviors. Further work is needed to establish how much of the observed neurobehavioral changes are due to direct effects of GEN compared to those attributed to gut dysbiosis/shifts in gut metabolite profiles. Usage of GF mice and post-biotic supplementation of GEN-induced metabolites will be useful in teasing apart these diverging mechanisms. Probiotic and post-biotic supplementation approaches might be used to prevent or remediate behavioral disturbances due to early GEN exposure.

\section{Supplementary data}

This is linked to the online version of the paper at https://doi.org/10.1530/ JOE-19-0214.

\section{Declaration of interest}

The authors declare that there is no conflict of interest that could be perceived as prejudicing the impartiality of the research reported.

\section{Funding}

The studies were supported by NIEHS 1R01ES025547 (C S R). L W S is supported in part by NSF awards NSF awards 1743594, 1340058, 1639618 and 1139489. The University of Missouri, Office of Research provided initial instrumental and continuing personnel funding for the MU Metabolomics Center.

\section{Author contribution statement}

B A M, L W S, T J and C S R designed the study. B A M, Y L, M J F, J M, W G H, $A K S, N J B, S J S$ and $Z L$ participated in data acquisition and analyses. $B A$ $M, Y L, J M, W$ G H, A K S, N J B, S J S, Z L, L W S, T J and C S R participated in interpretation of data. B A M, Y L, J M, N J B, S J S, Z L, L W S, T J and C S R drafted the manuscript. All authors revised the manuscript for intellectual content and approved the final version. C S R is the guarantor of this work.

\section{Acknowledgements}

The authors thank all of the undergraduate research students who helped take care of the mice.

\section{References}

Adgent MA, Daniels JL, Edwards LJ, Siega-Riz AM \& Rogan WJ 2011 Early-life soy exposure and gender-role play behavior in children. Environmental Health Perspectives 119 1811-1816. (https://doi. org/10.1289/ehp.1103579)

Arispe SA, Adams B \& Adams TE 2013 Effect of phytoestrogens on basal and GnRH-induced gonadotropin secretion. Journal of Endocrinology 219 243-250. (https://doi.org/10.1530/JOE-13-0158)

Bai G, Ni K, Tsuruta T \& Nishino N 2016 Dietary casein and soy protein isolate modulate the effects of raffinose and fructooligosaccharides on the composition and fermentation of gut microbiota in rats. Journal of Food Science 81 H2093-H2098. (https://doi.org/10.1111/17503841.13391)

Bercik P, Park AJ, Sinclair D, Khoshdel A, Lu J, Huang X, Deng Y, Blennerhassett PA, Fahnestock M, Moine D, et al. 2011 The anxiolytic effect of Bifidobacterium longum NCC3001 involves vagal pathways for gut-brain communication. Neurogastroenterology and Motility 23 1132-1139. (https://doi.org/10.1111/j.1365-2982.2011.01796.x)

Bharwani A, Mian MF, Surette MG, Bienenstock J \& Forsythe P 2017 Oral treatment with Lactobacillus rhamnosus attenuates behavioural deficits and immune changes in chronic social stress. BMC Medicine 157.

Bonaz B, Bazin T \& Pellissier S 2018 The vagus nerve at the interface of the microbiota-gut-brain axis. Frontiers in Neuroscience 12 49. (https:// doi.org/10.3389/fnins.2018.00049)

Borre YE, Moloney RD, Clarke G, Dinan TG \& Cryan JF 2014 The impact of microbiota on brain and behavior: mechanisms and therapeutic potential. Advances in Experimental Medicine and Biology 817 373-403. (https://doi.org/10.1007/978-1-4939-0897-4_17)

Braun JM, Kalkbrenner AE, Just AC, Yolton K, Calafat AM, Sjodin A, Hauser R, Webster GM, Chen A \& Lanphear BP 2014 Gestational exposure to endocrine-disrupting chemicals and reciprocal social, repetitive, and stereotypic behaviors in 4- and 5-year-old children: the HOME study. Environmental Health Perspectives 122 513-520.

Brielmaier J, Senerth JM, Silverman JL, Matteson PG, Millonig JH, DiCicco-Bloom E \& Crawley JN 2014 Chronic desipramine treatment rescues depression-related, social and cognitive deficits in Engrailed-2 knockout mice. Genes, Brain and Behavior 13 286-298.

Bristot Silvestrin R, Bambini-Junior V, Galland F, Daniele Bobermim L, Quincozes-Santos A, Torres Abib R, Zanotto C, Batassini C, Brolese G, Goncalves CA, et al. 2013 Animal model of autism induced by prenatal exposure to valproate: altered glutamate metabolism in the hippocampus. Brain Research 1495 52-60. (https://doi.org/10.1016/j. brainres.2012.11.048)

Buffington SA, Di Prisco GV, Auchtung TA, Ajami NJ, Petrosino JF \& Costa-Mattioli M 2016 Microbial reconstitution reverses maternal diet-induced social and synaptic deficits in offspring. Cell 165 1762-1775.

Caporaso JG, Kuczynski J, Stombaugh J, Bittinger K, Bushman FD, Costello EK, Fierer N, Pena AG, Goodrich JK, Gordon JI, et al. 2010 QIIME allows analysis of high-throughput community sequencing data. Nature Methods 7 335-336. (https://doi.org/10.1038/ nmeth.f.303)

Caporaso JG, Lauber CL, Walters WA, Berg-Lyons D, Lozupone CA, Turnbaugh PJ, Fierer N \& Knight R 2011 Global patterns of 16S rRNA diversity at a depth of millions of sequences per sample. PNAS 108 (Supplement 1) 4516-4522. (https://doi.org/10.1073/ pnas.1000080107)

Chau DK, Choi AY, Yang W, Leung WN \& Chan CW 2017 Downregulation of glutamatergic and GABAergic proteins in valproric acid associated social impairment during adolescence in mice. Behavioural Brain Research 316 255-260. (https://doi.org/10.1016/j. bbr.2016.09.003)

Chew V \& United S 1977 Comparisons among Treatment Means in an Analysis of Variance. Washington, DC, USA: Department of Agriculture, Agricultural Research Service. 
Cimafranca MA, Davila J, Ekman GC, Andrews RN, Neese SL, Peretz J, Woodling KA, Helferich WG, Sarkar J, Flaws JA, et al. 2010 Acute and chronic effects of oral genistein administration in neonatal mice. Biology of Reproduction 83 114-121. (https://doi.org/10.1095/ biolreprod.109.080549)

Clarke G, Grenham S, Scully P, Fitzgerald P, Moloney RD, Shanahan F, Dinan TG \& Cryan JF 2013 The microbiome-gut-brain axis during early life regulates the hippocampal serotonergic system in a sexdependent manner. Molecular Psychiatry 18 666-673. (https://doi. org/10.1038/mp.2012.77)

Crawley JN 2007 Mouse behavioral assays relevant to the symptoms of autism. Brain Pathology 17 448-459.

Cross TL, Zidon TM, Welly RJ, Park YM, Britton SL, Koch LG, Rottinghaus GE, de Godoy MRC, Padilla J, Swanson KS, et al. 2017 Soy improves cardiometabolic health and cecal microbiota in female low-fit rats. Scientific Reports 7 9261. (https://doi.org/10.1038/s41598017-08965-0)

D'Aloisio AA, DeRoo LA, Baird DD, Weinberg CR \& Sandler DP 2013 Prenatal and infant exposures and age at menarche. Epidemiology 24 277-284. (https://doi.org/10.1097/EDE.0b013e31828062b7)

Deda O, Chatziioannou AC, Fasoula S, Palachanis D, Raikos N, Theodoridis GA \& Gika HG 2017 Sample preparation optimization in fecal metabolic profiling. Journal of Chromatography: B, Analytical Technologies in the Biomedical and Life Sciences 1047 115-123. (https:// doi.org/10.1016/j.jchromb.2016.06.047)

DeSantis TZ, Hugenholtz P, Larsen N, Rojas M, Brodie EL, Keller K, Huber T, Dalevi D, Hu P \& Andersen GL 2006 Greengenes, a chimerachecked $16 \mathrm{~S}$ rRNA gene database and workbench compatible with ARB. Applied and Environmental Microbiology 72 5069-5072. (https:// doi.org/10.1128/AEM.03006-05)

Desbonnet L, Clarke G, Shanahan F, Dinan TG \& Cryan JF 2014 Microbiota is essential for social development in the mouse. Molecular Psychiatry 19 146-148. (https://doi.org/10.1038/mp.2013.65)

Diaz Heijtz R, Wang S, Anuar F, Qian Y, Bjorkholm B, Samuelsson A, Hibberd ML, Forssberg H \& Pettersson S 2011 Normal gut microbiota modulates brain development and behavior. PNAS 108 3047-3052. (https://doi.org/10.1073/pnas.1010529108)

Dinsdale EC \& Ward WE 2010 Early exposure to soy isoflavones and effects on reproductive health: a review of human and animal studies. Nutrients 2 1156-1187. (https://doi.org/10.3390/nu2111156)

Dodd D, Spitzer MH, Van Treuren W, Merrill BD, Hryckowian AJ, Higginbottom SK, Le A, Cowan TM, Nolan GP, Fischbach MA, et al. 2017 A gut bacterial pathway metabolizes aromatic amino acids into nine circulating metabolites. Nature 551 648-652. (https://doi. org/10.1038/nature24661)

Dolinoy DC, Weidman JR, Waterland RA \& Jirtle RL 2006 Maternal genistein alters coat color and protects Avy mouse offsping from obesity by modifying the fetal epigenome. Environmental Health Perspectives 114 567-572. (https://doi.org/10.1289/ehp.8700)

Dolinoy DC, Huang D \& Jirtle RL 2007 Maternal nutrient supplementation counteracts bisphenol A-induced DNA hypomethylation in early development. PNAS 104 13056-13061. (https://doi.org/10.1073/pnas.0703739104)

Dominguez-Ordonez R, Garcia-Juarez M, Lima-Hernandez FJ, GomoraArrati P, Blaustein JD \& Gonzalez-Flores O 2015 Sexual receptivity facilitated by unesterified estradiol: dependence on estrogen and progestin receptors and priming dose of estradiol benzoate. Behavioral Neuroscience 129 777-788. (https://doi.org/10.1037/bne0000103)

Dominguez-Ordonez R, Garcia-Juarez M, Lima-Hernandez FJ, GomoraArrati P, Blaustein JD, Etgen AM \& Gonzalez-Flores O 2016 Estrogen receptor alpha and beta are involved in the activation of lordosis behavior in estradiol-primed rats. Hormones and Behavior 86 1-7. (https://doi.org/10.1016/j.yhbeh.2016.08.010)

Edgar RC 2010 Search and clustering orders of magnitude faster than BLAST. Bioinformatics 26 2460-2461. (https://doi.org/10.1093/ bioinformatics/btq461)
Ey E, Yang M, Katz AM, Woldeyohannes L, Silverman JL, Leblond CS, Faure P, Torquet N, Le Sourd AM, Bourgeron T, et al. 2012 Absence of deficits in social behaviors and ultrasonic vocalizations in later generations of mice lacking neuroligin4. Genes, Brain and Behavior 11 928-941.

Fernandez-Raudales D, Hoeflinger JL, Bringe NA, Cox SB, Dowd SE, Miller MJ \& Gonzalez de Mejia E 2012 Consumption of different soymilk formulations differentially affects the gut microbiomes of overweight and obese men. Gut Microbes 3 490-500. (https://doi. org/10.4161/gmic.21578)

Frankiensztajn LM, Gur-Pollack R \& Wagner S 2018 A combinatorial modulation of synaptic plasticity in the rat medial amygdala by oxytocin, urocortin 3 and estrogen. Psychoneuroendocrinology 92 95-102. (https://doi.org/10.1016/j.psyneuen.2018.04.006)

Fritz WA, Wang J, Eltoum IE \& Lamartiniere CA 2002 Dietary genistein down-regulates androgen and estrogen receptor expression in the rat prostate. Molecular and Cellular Endocrinology 186 89-99. (https://doi. org/10.1016/S0303-7207(01)00663-3)

Fung LK \& Hardan AY 2015 Developing medications targeting glutamatergic dysfunction in autism: progress to date. CNS Drugs 29 453-463. (https://doi.org/10.1007/s40263-015-0252-0)

Gareau MG, Wine E, Rodrigues DM, Cho JH, Whary MT, Philpott DJ, Macqueen G \& Sherman PM 2011 Bacterial infection causes stressinduced memory dysfunction in mice. Gut $60307-317$. (https://doi. org/10.1136/gut.2009.202515)

González I, Lê Cao KA, Davis MJ \& Déjean S 2012 Visualising associations between paired 'omics' data sets. BioData Mining 5 19. (https://doi org/10.1186/1756-0381-5-19)

Han S, Tai C, Westenbroek RE, Yu FH, Cheah CS, Potter GB, Rubenstein JL, Scheuer T, de la Iglesia HO \& Catterall WA 2012 Autistic-like behaviour in Scn1a+/- mice and rescue by enhanced GABA-mediated neurotransmission. Nature 489 385-390. (https://doi. org/10.1038/nature11356)

Hartley DE, Edwards JE, Spiller CE, Alom N, Tucci S, Seth P, Forsling ML \& File SE 2003 The soya isoflavone content of rat diet can increase anxiety and stress hormone release in the male rat. Psychopharmacology 167 46-53. (https://doi.org/10.1007/s00213-0021369-7)

Heberle H, Meirelles GV, da Silva FR, Telles GP \& Minghim R 2015 InteractiVenn: a web-based tool for the analysis of sets through Venn diagrams. BMC Bioinformatics 16 169. (https://doi.org/10.1186/ s12859-015-0611-3)

Howdeshell KL 2002 A model of the development of the brain as a construct of the thyroid system. Environmental Health Perspectives 110 (Supplement 3) 337-348. (https://doi.org/10.1289/ ehp.02110s3337)

Hsiao EY, McBride SW, Hsien S, Sharon G, Hyde ER, McCue T, Codelli JA, Chow J, Reisman SE, Petrosino JF, et al. 2013 Microbiota modulate behavioral and physiological abnormalities associated with neurodevelopmental disorders. Cell 155 1451-1463. (https://doi. org/10.1016/j.cell.2013.11.024)

Huang G, Xu J, Cai D, Chen SY, Nagy T \& Guo TL 2018 Exacerbation of Type 1 diabetes in perinatally genistein exposed female non-obese diabetic (NOD) mouse is associated With alterations of gut microbiota and immune homeostasis. Toxicological Sciences 165 291-301. (https://doi.org/10.1093/toxsci/kfy162)

Jaglin M, Rhimi M, Philippe C, Pons N, Bruneau A, Goustard B, Dauge V, Maguin E, Naudon L \& Rabot S 2018 Indole, a signaling molecule produced by the gut microbiota, negatively impacts emotional behaviors in rats. Frontiers in Neuroscience 12 216. (https://doi. org/10.3389/fnins.2018.00216)

Jasarevic E, Sieli PT, Twellman EE, Welsh Jr TH, Schachtman TR, Roberts RM, Geary DC \& Rosenfeld CS 2011 Disruption of adult expression of sexually selected traits by developmental exposure to bisphenol A. PNAS 108 11715-11720. (https://doi.org/10.1073/ pnas.1107958108) 
Jasarevic E, Williams SA, Vandas GM, Ellersieck MR, Liao C, Kannan K, Roberts RM, Geary DC \& Rosenfeld CS 2013 Sex and dose-dependent effects of developmental exposure to bisphenol A on anxiety and spatial learning in deer mice (Peromyscus maniculatus bairdii) offspring. Hormones and Behavior 63 180-189. (https://doi.org/10.1016/j. yhbeh.2012.09.009)

Javurek AB, Spollen WG, Johnson SA, Bivens NJ, Bromert KH, Givan SA \& Rosenfeld CS 2016 Effects of exposure to bisphenol A and ethinyl estradiol on the gut microbiota of parents and their offspring in a rodent model. Gut Microbes 7 471-485. (https://doi.org/10.1080/1949 0976.2016.1234657)

Jefferson WN \& Williams CJ 2011 Circulating levels of genistein in the neonate, apart from dose and route, predict future adverse female reproductive outcomes. Reproductive Toxicology 31 272-279. (https:// doi.org/10.1016/j.reprotox.2010.10.001)

Jefferson WN, Padilla-Banks E \& Newbold RR 2007 Disruption of the developing female reproductive system by phytoestrogens: genistein as an example. Molecular Nutrition and Food Research 51 832-844. (https://doi.org/10.1002/mnfr.200600258)

Johnson SA, Javurek AB, Painter MS, Peritore MP, Ellersieck MR, Roberts RM \& Rosenfeld CS 2015 Disruption of parenting behaviors in California mice, a monogamous rodent species, by endocrine disrupting chemicals. PLOS ONE 10 e0126284. (https://doi. org/10.1371/journal.pone.0126284)

Johnson SA, Painter MS, Javurek AB, Murphy CR, Howald EC, Khan ZZ, Conard CM, Gant KL, Ellersieck MR, Hoffmann F, et al. 2017 Characterization of vocalizations emitted in isolation by California mouse (Peromyscus californicus) pups throughout the postnatal period. Journal of Comparative Psychology 131 30-39. (https://doi. org/10.1037/com0000057)

Johnson SA, Farrington MJ, Murphy CR, Caldo PD, McAllister LA, Kaur S, Chun C, Ortega MT, Marshall BL, Hoffmann F, et al. 2018 Multigenerational effects of bisphenol A or ethinyl estradiol exposure on F2 California mice (Peromyscus californicus) pup vocalizations. PLOS ONE 13 e0199107. (https://doi.org/10.1371/journal. pone.0199107)

Lei Z, Li H, Chang J, Zhao PX \& Sumner LW 2012 MET-IDEA version 2.06; improved efficiency and additional functions for mass spectrometry-based metabolomics data processing. Metabolomics 8 105-110. (https://doi.org/10.1007/s11306-012-0397-5)

Levy JR, Faber KA, Ayyash L \& Hughes Jr CL 1995 The effect of prenatal exposure to the phytoestrogen genistein on sexual differentiation in rats. Proceedings of the Society for Experimental Biology and Medicine 208 60-66. (https://doi.org/10.3181/00379727-208-43832)

Liu RT 2017 The microbiome as a novel paradigm in studying stress and mental health. American Psychologist 72 655-667. (https://doi. org/10.1037/amp0000058)

Lopez P, Sanchez M, Perez-Cruz C, Velazquez-Villegas LA, Syeda T, Aguilar-Lopez M, Rocha-Viggiano AK, Del Carmen Silva-Lucero M, Torre-Villalvazo I, Noriega LG, et al. 2018 Long-term genistein consumption modifies gut microbiota, improving glucose metabolism, metabolic endotoxemia, and cognitive function in mice fed a high-fat diet. Molecular Nutrition and Food Research 62 e1800313. (https://doi.org/10.1002/mnfr.201800313)

Love MI, Huber W \& Anders S 2014 Moderated estimation of fold change and dispersion for RNA-seq data with DESeq2. Genome Biology 15550 (https://doi.org/10.1186/s13059-014-0550-8)

Loy A, Maixner F, Wagner M \& Horn M 2007 probeBase - an online resource for rRNA-targeted oligonucleotide probes: new features 2007 Nucleic Acids Research 35 D800-D804. (https://doi.org/10.1093/nar/ gkl856)

Ma J, Prince AL, Bader D, Hu M, Ganu R, Baquero K, Blundell P, Alan Harris R, Frias AE, Grove KL, et al. 2014 High-fat maternal diet during pregnancy persistently alters the offspring microbiome in a primate model. Nature Communications 5 3889. (https://doi.org/10.1038/ ncomms4889)
Magoc T \& Salzberg SL 2011 FLASH: fast length adjustment of short reads to improve genome assemblies. Bioinformatics 27 2957-2963. (https:// doi.org/10.1093/bioinformatics/btr507)

McMurdie PJ \& Holmes S 2013 Phyloseq: an R package for reproducible interactive analysis and graphics of microbiome census data. PLoS ONE 8 e61217. (https://doi.org/10.1371/journal.pone.0061217)

Medigovic I, Manojlovic-Stojanoski M, Trifunovic S, Ristic N, Milosevic V, Zikic D \& Nestorovic N 2012 Effects of genistein on gonadotropic cells in immature female rats. Acta Histochemica 114 270-275. (https://doi.org/10.1016/j.acthis.2011.06.003)

Moy SS, Nadler JJ, Perez A, Barbaro RP, Johns JM, Magnuson TR, Piven J \& Crawley JN 2004 Sociability and preference for social novelty in five inbred strains: an approach to assess autistic-like behavior in mice. Genes, Brain, and Behavior 3 287-302. (https://doi.org/10.1111/j.16011848.2004.00076.x)

Mueller JK \& Heger S 2014 Endocrine disrupting chemicals affect the gonadotropin releasing hormone neuronal network. Reproductive Toxicology 44 73-84. (https://doi.org/10.1016/j.reprotox.2013.10.011)

Nakatsu CH, Armstrong A, Clavijo AP, Martin BR, Barnes S \& Weaver CM 2014 Fecal bacterial community changes associated with isoflavone metabolites in postmenopausal women after soy bar consumption. PLOS ONE 9 e108924. (https://doi.org/10.1371/journal. pone.0108924)

Neufeld KM, Kang N, Bienenstock J \& Foster JA 2011 Reduced anxietylike behavior and central neurochemical change in germ-free mice. Neurogastroenterology and Motility 23 255.e119-264.e119. (https://doi. org/10.1111/j.1365-2982.2010.01620.x)

Okamoto Y, Aoki A, Ueda K \& Jinno H 2018 Metabolomic analysis uncovered an association of serum phospholipid levels with estrogeninduced mammary tumors in female $\mathrm{ACI} / \mathrm{Seg}$ rats. Toxicology Letters 288 65-70. (https://doi.org/10.1016/j.toxlet.2018.02.017)

Paul B, Royston KJ, Li Y, Stoll ML, Skibola CF, Wilson LS, Barnes S, Morrow CD \& Tollefsbol TO 2017 Impact of genistein on the gut microbiome of humanized mice and its role in breast tumor inhibition. PLOS ONE 12 e0189756. (https://doi.org/10.1371/journal. pone.0189756)

Petra AI, Panagiotidou S, Hatziagelaki E, Stewart JM, Conti P \& Theoharides TC 2015 Gut-microbiota-brain axis and its effect on neuropsychiatric disorders With suspected immune dysregulation. Clinical Therapeutics 37 984-995. (https://doi.org/10.1016/j. clinthera.2015.04.002)

Piacentini G, Peroni D, Bessi E \& Morelli L 2010 Molecular characterization of intestinal microbiota in infants fed with soymilk. Journal of Pediatric Gastroenterology and Nutrition 51 71-76. (https:// doi.org/10.1097/MPG.0b013e3181dc8b02)

Piccolo BD, Mercer KE, Bhattacharyya S, Bowlin AK, Saraf MK, Pack L, Chintapalli SV, Shankar K, Adams SH, Badger TM, et al. 2017 Early postnatal diets affect the bioregional small intestine microbiome and ileal metabolome in neonatal pigs. Journal of Nutrition $\mathbf{1 4 7}$ 1499-1509. (https://doi.org/10.3945/jn.117.252767)

Politte LC, Henry CA \& McDougle CJ 2014 Psychopharmacological interventions in autism spectrum disorder. Harvard Review of Psychiatry 22 76-92. (https://doi.org/10.1097/ HRP.0000000000000030)

Ponti G, Rodriguez-Gomez A, Farinetti A, Marraudino M, Filice F, Foglio B, Sciacca G, Panzica GC \& Gotti S 2017 Early postnatal genistein administration permanently affects nitrergic and vasopressinergic systems in a sex-specific way. Neuroscience 346 203-215. (https://doi.org/10.1016/j.neuroscience.2017.01.024)

Rice D \& Barone Jr S 2000 Critical periods of vulnerability for the developing nervous system: evidence from humans and animal models. Environmental Health Perspectives 108 (Supplement 3) 511-533. (https://doi.org/10.1289/ehp.00108s3511)

Rock KD, Horman B, Phillips AL, McRitchie SL, Watson S, Deese-Spruill J, Jima D, Sumner S, Stapleton HM \& Patisaul HB 2018 EDC IMPACT: molecular effects of developmental FM 550 exposure in Wistar 
rat placenta and fetal forebrain. Endocrine Connections 7 305-324. (https://doi.org/10.1530/EC-17-0373)

Rodriguez-Gomez A, Filice F, Gotti S \& Panzica G 2014 Perinatal exposure to genistein affects the normal development of anxiety and aggressive behaviors and nitric oxide system in CD1 male mice. Physiology and Behavior 133 107-114. (https://doi.org/10.1016/j. physbeh.2014.05.020)

Rohart F, Gautier B, Singh A \& Le Cao KA 2017 mixOmics: an R package for 'omics feature selection and multiple data integration. PLoS Computational Biology 13 e1005752. (https://doi.org/10.1371/journal. pcbi.1005752)

Rosenfeld CS 2015 Microbiome disturbances and autism spectrum disorders. Drug Metabolism and Disposition 43 1557-1571. (https://doi. org/10.1124/dmd.115.063826)

Rosenfeld CS \& Trainor BC 2014 Environmental health factors and sexually dimorphic differences in behavioral disruptions. Current Environmental Health Reports 1 287-301.

Rosenfeld CS, Javurek AB, Johnson SA, Lei Z, Sumner LW \& Hess RA 2018 Seminal fluid metabolome and epididymal changes after antibiotic treatment in mice. Reproduction 156 1-10. (https://doi.org/10.1530/ REP-18-0072)

Rosenfeld CS, Sieli PT, Warzak DA, Ellersieck MR, Pennington KA \& Roberts RM 2013 Maternal exposure to bisphenol A and genistein has minimal effect on $\mathrm{A}(\mathrm{vy}) / \mathrm{a}$ offspring coat color but favors birth of agouti over nonagouti mice. PNAS 110 537-542. (https://doi. org/10.1073/pnas.1220230110)

Ryan BC, Young NB, Crawley JN, Bodfish JW \& Moy SS 2010 Social deficits, stereotypy and early emergence of repetitive behavior in the C58/J inbred mouse strain. Behavioural Brain Research 208 178-188.

Santti R, Makela S, Strauss L, Korkman J \& Kostian ML 1998 Phytoestrogens: potential endocrine disruptors in males. Toxicology and Industrial Health 14 223-237. (https://doi. org/10.1177/074823379801400114)

Saville DJ 1990 Multiple comparison procedures: the practical solution American Statistician 44 174-180. (https://doi.org/10.1080/00031305. 1990.10475712)

Scallet AC, Wofford M, Meredith JC, Allaben WT \& Ferguson SA 2003 Dietary exposure to genistein increases vasopressin but does not alter beta-endorphin in the rat hypothalamus. Toxicological Sciences $\mathbf{7 2}$ 296-300. (https://doi.org/10.1093/toxsci/kfg029)

Schug TT, Blawas AM, Gray K, Heindel JJ \& Lawler CP 2015 Elucidating the links between endocrine disruptors and neurodevelopment. Endocrinology 156 1941-1951.

Schugar RC, Willard B, Wang Z \& Brown JM 2017 Postprandial gut microbiota-driven choline metabolism links dietary cues to adipose tissue dysfunction. Adipocyte 7 49-56. (https://doi.org/10.1080/21623 945.2017.1398295)

Sgritta M, Dooling SW, Buffington SA, Momin EN, Francis MB, Britton RA \& Costa-Mattioli M 2019 Mechanisms underlying microbial-mediated changes in social behavior in mouse models of autism spectrum disorder. Neuron 101 246.e246-259.e246.

Silverman JL, Yang M, Lord C \& Crawley JN 2010 Behavioural phenotyping assays for mouse models of autism. Nature Reviews: Neuroscience 11 490-502.

Smith-Brown P, Morrison M, Krause L \& Davies PS 2016 Dairy and plant based food intakes are associated with altered faecal microbiota in 2 to 3 year old Australian children. Scientific Reports 6 32385. (https:// doi.org/10.1038/srep32385)

Steel RG 1997 Principles and Procedures of Statistics: A Biometrical Approach. New York, NY, USA: McGraw-Hill Higher Education.

Stilling RM, Dinan TG \& Cryan JF 2014 Microbial genes, brain and behaviour - epigenetic regulation of the gut-brain axis. Genes, Brain, and Behavior 13 69-86. (https://doi.org/10.1111/gbb.12109)

Sudo N, Chida Y, Aiba Y, Sonoda J, Oyama N, Yu XN, Kubo C \& Koga Y 2004 Postnatal microbial colonization programs the hypothalamic-pituitary-adrenal system for stress response in mice. Journal of Physiology 558 263-275. (https://doi.org/10.1113/ jphysiol.2004.063388)

Sumner LW, Amberg A, Barrett D, Beale MH, Beger R, Daykin CA, Fan TW, Fiehn O, Goodacre R, Griffin JL, et al. 2007 Proposed minimum reporting standards for chemical analysis Chemical Analysis Working Group (CAWG) Metabolomics Standards Initiative (MSI). Metabolomics 3 211-221. (https://doi.org/10.1007/s11306-007-0082-2)

Thorburn AN, McKenzie CI, Shen S, Stanley D, Macia L, Mason LJ, Roberts LK, Wong CH, Shim R, Robert R, et al. 2015 Evidence that asthma is a developmental origin disease influenced by maternal diet and bacterial metabolites. Nature Communications 6 7320. (https://doi. org/10.1038/ncomms8320)

Trifunovic S, Manojlovic-Stojanoski M, Ajdzanovic V, Nestorovic N, Ristic N, Medigovic I \& Milosevic V 2012 Genistein stimulates the hypothalamo-pituitary-adrenal axis in adult rats: morphological and hormonal study. Histology and Histopathology 27 627-640. (https://doi. org/10.14670/HH-27.627)

Tso IF, Fang Y, Phan KL, Welsh RC \& Taylor SF 2015 Abnormal GABAergic function and face processing in schizophrenia: a pharmacologic-fMRI study. Schizophrenia Research 168 338-344. (https://doi.org/10.1016/j. schres.2015.08.022)

Upson K, Harmon QE, Laughlin-Tommaso SK, Umbach DM \& Baird DD 2016 Soy-based infant formula feeding and heavy menstrual bleeding among young African American women. Epidemiology 27 716-725. (https://doi.org/10.1097/EDE.0000000000000508)

van de Wouw M, Schellekens H, Dinan TG \& Cryan JF 2017 Microbiotagut-brain axis: modulator of host metabolism and appetite. Journal of Nutrition 147 727-745. (https://doi.org/10.3945/jn.116.240481)

Vieira-Potter VJ, Cross TL, Swanson KS, Sarma SJ, Lei Z, Sumner LW \& Rosenfeld CS 2018 Soy-induced fecal metabolome changes in ovariectomized and intact female rats: relationship with cardiometabolic health. Scientific Reports 8 16896. (https://doi. org/10.1038/s41598-018-35171-3)

Viglietti-Panzica C, Mura E \& Panzica G 2007 Effects of early embryonic exposure to genistein on male copulatory behavior and vasotocin system of Japanese quail. Hormones and Behavior 51 355-363. (https:// doi.org/10.1016/j.yhbeh.2006.12.003)

Walters WA, Caporaso JG, Lauber CL, Berg-Lyons D, Fierer N \& Knight R 2011 PrimerProspector: de novo design and taxonomic analysis of barcoded polymerase chain reaction primers. Bioinformatics $\mathbf{2 7}$ 1159-1161. (https://doi.org/10.1093/bioinformatics/btr087)

Wei H, Ding C, Jin G, Yin H, Liu J \& Hu F 2015 Abnormal glutamate release in aged BTBR mouse model of autism. International Journal of Clinical and Experimental Pathology 8 10689-10697.

Westmark CJ 2013 Soy infant formula may be associated with autistic behaviors. Autism-Open Access 3 20727. (https://doi. org/10.4172/2165-7890.1000120)

Williams SA, Jasarevic E, Vandas GM, Warzak DA, Geary DC, Ellersieck MR, Roberts RM \& Rosenfeld CS 2013 Effects of developmental bisphenol A exposure on reproductive-related behaviors in California mice (Peromyscus californicus): a monogamous animal model. PLoS ONE 8 e55698. (https://doi.org/10.1371/journal. pone.0055698)

Wisniewski AB, Cernetich A, Gearhart JP \& Klein SL 2005 Perinatal exposure to genistein alters reproductive development and aggressive behavior in male mice. Physiology and Behavior 84 327-334. (https:// doi.org/10.1016/j.physbeh.2004.12.008)

Wojcik-Gladysz A, Romanowicz K, Misztal T, Polkowska J \& Barcikowski B 2005 Effects of intracerebroventricular infusion of genistein on the secretory activity of the GnRH/LH axis in ovariectomized ewes. Animal Reproduction Science 86 221-235. (https://doi.org/10.1016/j. anireprosci.2004.08.004)

Wu GD, Compher C, Chen EZ, Smith SA, Shah RD, Bittinger K, Chehoud C, Albenberg LG, Nessel L, Gilroy E, et al. 2016 Comparative https://joe.bioscientifica.com https://doi.org/10.1530/JOE-19-0214 (c) 2019 Society for Endocrinology Published by Bioscientifica Ltd. Printed in Great Britain 
metabolomics in vegans and omnivores reveal constraints on dietdependent gut microbiota metabolite production. Gut 65 63-72. (https://doi.org/10.1136/gutjnl-2014-308209)

Yang M, Zhodzishsky V \& Crawley JN 2007 Social deficits in BTBR T+tf/J mice are unchanged by cross-fostering with C57BL/6J mothers. International Journal of Developmental Neuroscience 25 515-521. (https://doi.org/10.1016/j.ijdevneu.2007.09.008)

Yeruva L, Spencer NE, Saraf MK, Hennings L, Bowlin AK, Cleves MA, Mercer K, Chintapalli SV, Shankar K, Rank RG, et al. 2016 Formula diet alters small intestine morphology, Microbial abundance and reduces VE-cadherin and IL-10 expression in neonatal porcine model. BMC Gastroenterology 16 40. (https://doi.org/10.1186/s12876-0160456-x)

Yoshimura R, Yamamoto E \& Endo Y 2011 Morphological effects of isoflavones (daidzein and genistein) on hypothalamic oxytocin neurons in the neonatal mouse brain slice cultures. Neuroscience Letters 505 87-92. (https://doi.org/10.1016/j.neulet.2011.09.067)

Zheng H, Powell JE, Steele MI, Dietrich C \& Moran NA 2017 Honeybee gut microbiota promotes host weight gain via bacterial metabolism and hormonal signaling. PNAS 114 4775-4780. (https://doi. org/10.1073/pnas.1701819114)

Zhou CB \& Fang JY 2018 The regulation of host cellular and gut microbial metabolism in the development and prevention of colorectal cancer. Critical Reviews in Microbiology 44 436-454. (https:// doi.org/10.1080/1040841X.2018.1425671)

Zhou L, Xiao X, Zhang Q, Zheng J, Li M, Yu M, Wang X, Deng M, Zhai X \& Li R 2018 Improved glucose and lipid metabolism in the early life of female offspring by maternal dietary genistein is associated with alterations in the gut microbiota. Frontiers in Endocrinology 9516. (https://doi.org/10.3389/fendo.2018.00516)

Received in final form 31 May 2019

Accepted 10 June 2019

Accepted Preprint published online 10 June 2019 (c) 2019 Society for Endocrinology Published by Bioscientifica Ltd.
Printed in Great Britain 